Daniela Batista de Almeida Freitas

\title{
Avaliação das metástases encefálicas antes e após radiocirurgia através de técnica de permeabilidade por ressonância magnética
}

\author{
Tese apresentada à Faculdade de Medicina da \\ Universidade de São Paulo para obtenção do \\ título de Doutor em Ciências \\ Programa de Radiologia \\ Orientadora: Profa. Dra. Claudia Costa Leite \\ Coorientadora: Dra. Maria Concepcion Garcia \\ Otaduy
}

São Paulo

2015 
Dados Internacionais de Catalogação na Publicação (CIP)

Preparada pela Biblioteca da

Faculdade de Medicina da Universidade de São Paulo

Creprodução autorizada pelo autor

Freitas, Daniela Batista de Almeida

Avaliação das metástases encefálicas ante e após radiocirurgia através de técnica de permeabilidade por ressonância magnética / Daniela Batista de Almeida Freitas. -São Paulo, 2015.

Tese(doutorado)--Faculdade de Medicina da Universidade de São Paulo. Programa de Radiologia.

Orientadora: Claudia Costa Leite.

Coorientadora: Maria Concepcion Garcia Otaduy.

Descritores: 1.Espectroscopia de ressonância magnética 2.Metástase neoplásica 3.Encéfalo 4.Neoplasias encefálicas 5.Radiocirurgia 6.Permeabilidade capilar

USP/FM/DBD-072/15 


\section{DEDICATÓRIA}

Aos meus pais Aroldo e Venia, ao meu marido Daniel

e aos meus filhos Bernardo e Clara 


\section{AGRADECIMENTOS}

À minha família: meus pais Aroldo e Venia e irmã Renilde, pelo apoio em todos os momentos.

Ao meu marido Daniel, pela companhia e pela ajuda no desenvolvimento deste estudo.

À Professora Claudia Leite e Dra. Maria Otaduy, pela dedicação na orientação.

Ao Dr. Marco da Cunha Pinho pela ajuda na execução do projeto e revisão do texto.

Aos colegas da Radioterapia do INRAD, pela ajuda com o recrutamento dos pacientes do estudo.

Aos secretários Talita e Cesar, do ICESP, pela ajuda na marcação dos exames.

Ao Sr. Eduardo Figueiredo, pela ajuda no desenvolvimento da sequência de RM.

À equipe de tecnólogos do ICESP, pela ajuda na realização dos exames.

Aos professores do setor de neurorradiologia do INRAD, em especial Gabriel Gattas, Leandro Tavares Lucato e Edson Amaro Júnior, pela ajuda em vários momentos.

Aos residentes, estagiários, professores e funcionários do Departamento de Radiologia do ICESP e INRAD, com quem convivi nos últimos anos.

Aos professores John Hesselink, Nickdorth Farid, Carrie Macdonalds, Anders Dale e William Bradley Jr., da Universidade da Califórnia de San Diego, pelo apoio e orientação.

À Coordenação de Aperfeiçoamento de Pessoal de Nível Superior (CAPES) pelo apoio financeiro. 
Esta tese está de acordo com as seguintes normas, em vigor no momento desta publicação:

Referências: adaptado de International Committee of Medical Journals Editors (Vancouver).

Universidade de São Paulo. Faculdade de Medicina. Divisão de Biblioteca e Documentação. Guia de apresentação de dissertações, teses e monografias. Elaborado por Anneliese Carneiro da Cunha, Maria Julia de A. L. Freddi, Maria F. Crestana, Marinalva de Souza Aragão, Suely Campos Cardoso, Valéria Vilhena. 3a ed. São Paulo: Divisão de Biblioteca e Documentação; 2011.

Abreviaturas dos títulos dos periódicos de acordo com List of Journals Indexed in Index Medicus. 


\section{SUMÁRIO}

AGRADECIMENTOS

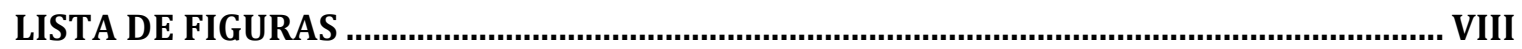

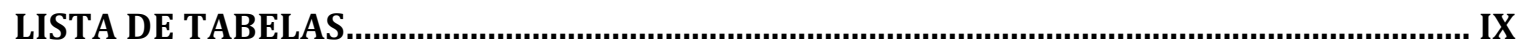

LISTA DE ABREVIATURAS, SIGLAS E SÍMBOLOS ...........................................................

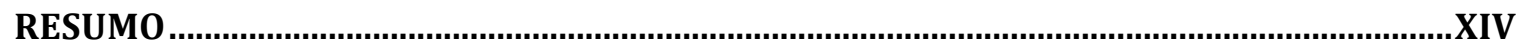

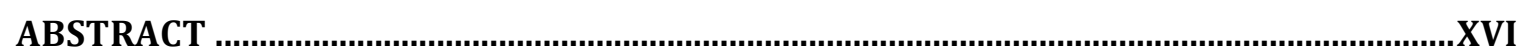

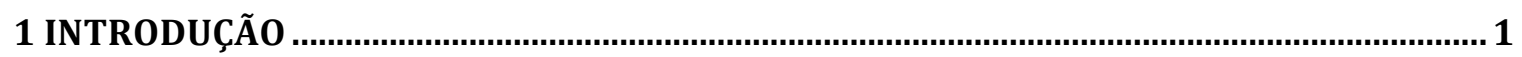

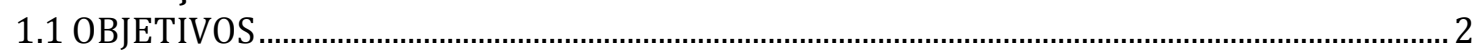

2 REVISÃO DA LITERATURA

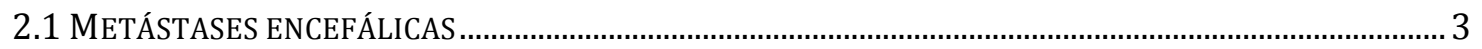

2.2 RADIOCIRURGIA ESTEREOTÁTICA NO TRATAMENTO DAS METÁSTASES ENCEFÁLICAS ........................... 4

2.3 AVALIAÇÃO DAS METÁSTASES ENCEFÁLICAS TRATADAS COM RADIOCIRURGIA ATRAVÉS DA RESSONÂNCIA MAGNÉTICA...........................................................................................................

2.4 AVALIAÇÃO DA PERMEABILIDADE TUMORAL POR RESSONÂNCIA MAGNÉTICA .................................. 12

2.4.1 Papel da Barreira Hematoencefálica nos Tumores Cerebrais ....................................... 13

2.4.2 Avaliação da permeabilidade da barreira hematoencefálica............................................ 13

2.4.3 Modelo Farmacocinético de Estimativa da Permeabilidade da Barreira

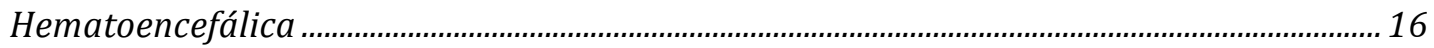

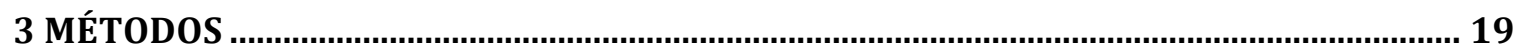

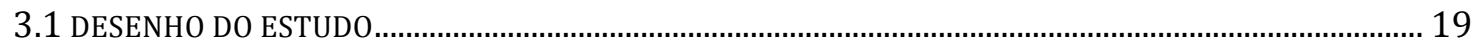

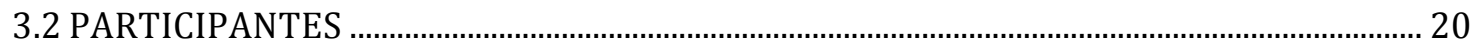

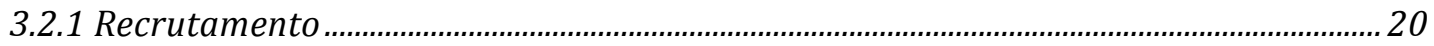

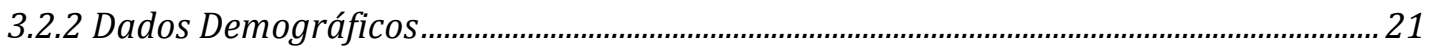

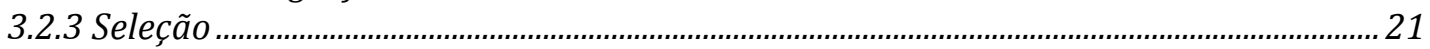

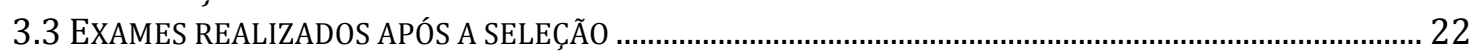

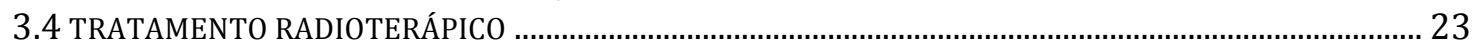

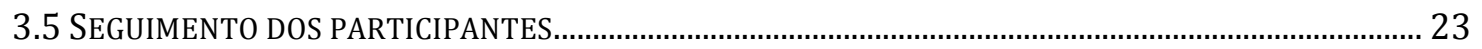

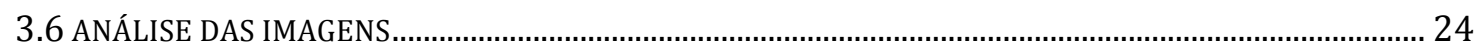

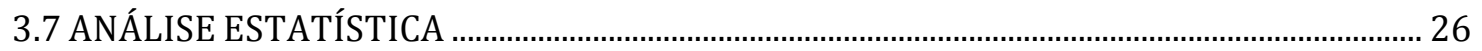

3.7.1 Cálculo do Tamanho Amostral..........................................................................................26

3.7.2 Estatística Descritiva............................................................................................................26

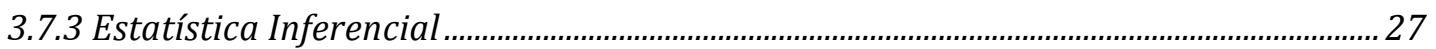

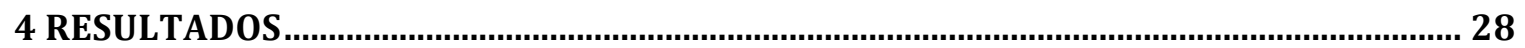

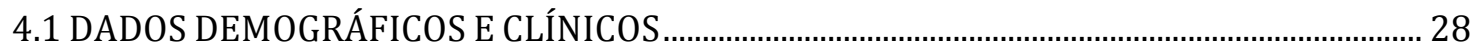

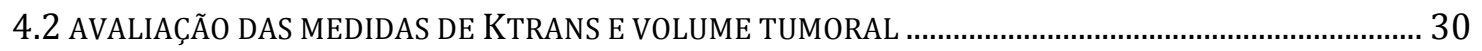

4.3 AVALIAÇÃO DA RESPOSTA VOLUMÉTRICA TUMORAL A MÉDIO PRAZO ….......................................... 31

4.4 RELAÇÃO ENTRE AS ALTERAÇÕES DAS MEDIDAS DE KTRANS E A RESPOSTA VOLUMÉTRICA

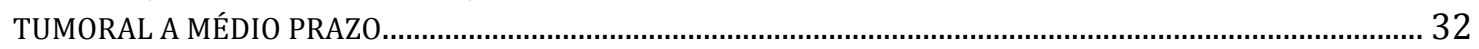

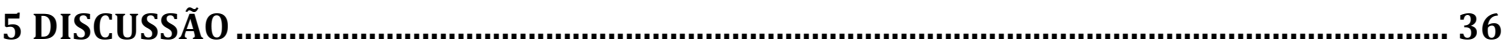

5.1 ESTUDO DA PERMEABILIDADE DA BARREIRA HEMATOENCEFÁLICA POR RESSONÂNCIA MAGNÉTICA

5.2 PERMEABILIDADE DAS LESÕES METASTÁTICAS ENCEFÁLICAS TRATADAS COM RADIOCIRURGIA ..... 38

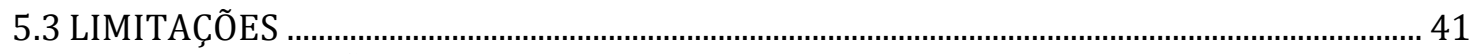

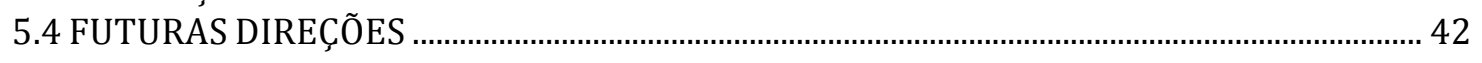

6 CONCLUSÕES 
7 REFERÊNCIAS

ANEXOS

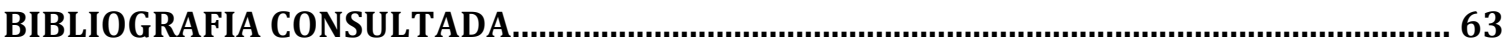




\section{LISTA DE FIGURAS}

Figura 1 Metástases encefálicas em exame de ressonância magnética (RM). 4

Figura 2. Esquema gráfico da técnica de radiocirurgia estereotática com acelerador linear. 5

Figura 3 Evolução por imagem de metástase cerebral tratada por radiocirurgia...... 8

Figura 4. Metástase cerebral com boa resposta terapêutica após radicocirurgia.....10

Figura 6. Esquema gráfico para avaliação da permeabilidade.............................................14

Figura 7. Imagens de RM para avaliação da permeabilidade.............................................16

Figura 8. Algoritmo descrevendo desenho do estudo.....................................................20

Figura 9. Curvas estimativas de falha de Kaplan-Meier avaliando a resposta volumétrica tumoral a médio prazo, comparando-se as lesões com aumento do Ktrans versus aquelas com diminuição do Ktrans após radiocirurgia estereotática

Figura 10. Curva ROC da razão de Ktrans para a previsão da resposta volumétrica tumoral a médio prazo.

Figura 11. Redução volumétrica tumoral (caso 6). .34

Figura 12. Progressão volumétrica tumoral (caso 11). 35 


\section{LISTA DE TABELAS}

Tabela 1: Dados demográficos e clínicos dos participantes

Tabela 2: Descrição do curso temporal das medidas de Ktrans e volume tumoral das

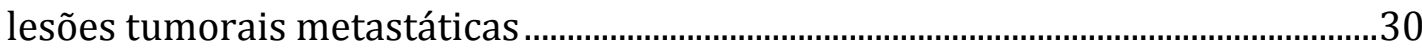

Tabela 3: Correlação entre as medidas de Ktrans e de volume tumoral.........................31 


\section{LISTA DE ABREVIATURAS, SIGLAS E SÍMBOLOS}

al. da expressão latina et alii - e outros

ASL do inglês, Arterial Spin Labeling

BSBM do inglês, Basic Score for Brain Metastases

$\mathbf{c m} / \mathbf{s} \quad$ Centímetros por segundo

$\mathbf{c m}^{\mathbf{3}} \quad$ Centímetros cúbicos

CAD Coeficiente Aparente de Difusão

Co Colina

Colasma Concentração no Plasma

CEE Concentração no Espaço Extracelular

DP Desvio-padrão

EEE Espaço Extravascular Extracelular

FOV do inglês, Field of View

GPA do inglês, Graded Prognostic Assessment

GRE do inglês, gradient echo

IC Intervalo de confiança 
ICESP Instituto do Câncer de São Paulo

INRAD Instituto de Radiologia

KPS do inglês, Karnofsky Performance Status

Ktrans Coeficiente de transferência (do inglês transfer co)

Ltd. Limitada, do inglês Limited

Min Minuto

$\mathrm{mL} / \mathrm{min} \quad$ Mililitro por minuto

$\mathrm{mL} / \mathrm{s} \quad$ Mililitro por segundo

mm Milímetro

$\mathbf{m m}^{2} \quad$ Milímetro quadrado

$\mathbf{m m}^{3} \quad$ Milímetro cúbico

$\mathrm{mmol} / \mathrm{Kg}$ Milimol por kilograma

N Frequência absoluta

NEX Número de Excitações

p Probabilidade estatística

Q1 Quartil inferior 
Q3 Quartil superior

$r \quad$ Coeficiente de correlação de Spearman

RC Radiocirurgia

RM Ressonância Magnética

ROC do inglês, Receiver Operating Characteristic

RPA do inglês, Recursive Partitioning Analysis

ROI Região de interesse

S Segundo

SIR do inglês, Score Index for Radiosurgery

SPECT Tomografia computadorizada por emissão de fótons

T Tesla

T1 Tempo de relaxação T1

T2 Tempo de decaimento T2

T2* Tempo de decaimento T2 gradiente

TE Tempo de Eco 
TI Tempo de Inversão

TR Tempo de Repetição

Ve $\quad$ Fração de volume do tecido

VSC Volume Sanguíneo Cerebral

Vs. Versus

$\% \quad$ Porcentagem

- Grau

$<\quad$ Menor

$=\quad$ Igual 


\section{RESUMO}

Freitas DBA. Avaliação das metástases encefálicas antes e após radiocirurgia através de técnica de permeabilidade por ressonância magnética [Tese]. São Paulo: Faculdade de Medicina, Universidade de São Paulo; 2015.

Objetivo: Avaliar o efeito da radiocirurgia estereotática (RC) sobre a permeabilidade tumoral das metástases encefálicas, utilizando-se como parâmetro a o coeficiente de transferência de contraste (transfer coefficient, Ktrans) obtida pela técnica de permeabilidade por ressonância magnética (RM). Objetivou-se também avaliar a capacidade de medições Ktrans para prever a resposta volumétrica tumoral a médio prazo depois da RC. Métodos: Vinte e seis pacientes adultos com um total de 34 metástases encefálicas foram submetidos a exames de RM, com sequência dinâmica ponderada em T1, após administração de contraste, em magneto de 1,5 T, antes da RC (linha de base) e 4-8 semanas após o tratamento. A partir desta sequência, foram obtidos mapas paramétricos Ktrans e realizadas medições em regiões de interesse das lesões. Adicionalmente, imagens convencionais ponderadas em T1 pós-contraste foram obtidas pelo menos 16 semanas após a RC, a fim de avaliar a resposta volumétrica tumoral baseada na variação de volume. Resultados: A média \pm (devio-padrão [DP]) do valor de Ktrans foi 0,13 \pm 0,11 $\mathrm{min}^{-1}$ no exame inicial e $0,08 \pm 0,07 \mathrm{~min}^{-1}$ após $4-8$ semanas do tratamento $(p<0,001)$. Os pacientes foram seguidos em média por 7,9 $\pm 4,7$ meses. Dezessete deles (22 lesões) foram submetidos a RM após 16 semanas do tratamento. Destes, 9 (41\%) lesões tinham progredido no médio prazo. O aumento da medida de Ktrans após $\mathrm{RC}$ foi preditivo de progressão do volume tumoral (taxa de risco $=1,50$, interval de confiança 95\%: 1,16-1,70, p < 0,001), sendo que a elevação em 15\% do valor de Ktrans mostrou uma sensibilidade de $78 \%$ e uma especificidade de $85 \%$ para a previsão de progressão do volume tumoral a médio prazo. Conclusão: RC está associada a redução dos valores Ktrans das metástases encefálicas no período pós-tratamento precoce. Além disso a variação Ktrans, medida através da técnica de permabilidade por RM, pode ser útil para prever a resposta do 
volume tumoral a médio prazo para este tratamento.

Descritores: espectroscopia de ressonância magnética; metástase neoplásica; encéfalo; neoplasias encefálicas; radiocirurgia; permeabilidade capilar. 


\section{ABSTRACT}

FREITAS DBA. Assessment of irradiated brain metastases using dynamic contrast-enhanced magnetic resonance imaging [Thesis]. São Paulo: "Faculdade de Medicina, Universidade de São Paulo; 2015.

Purpose: The purpose of this study was to evaluate the effect of stereotactic radiosurgery (SRS) on cerebral metastases using the transfer coefficient (Ktrans) assessed with dynamic contrast-enhanced (DCE) MRI. Furthermore, we aimed to evaluate the ability of Ktrans measurements to predict mid-term tumor outcomes after SRS. Methods:_Twenty-six adult patients with a total of 34 cerebral metastases underwent T1-weighted DCE MRI in a 1.5T magnet at baseline (prior to SRS) and 4-8 weeks after treatment. Quantitative analysis of DCE MRI was performed generating Ktrans parametric maps, and region-of-interest-based measurements were acquired for each metastasis. Conventional MRI was performed at least 16 weeks after SRS to assess mid-term tumor outcome using volume variation. Results: The mean \pm (Standard Deviation[SD]) Ktrans value was $0.13 \pm 0.11 \mathrm{~min}^{-1}$ at baseline and $0.08 \pm 0.07 \mathrm{~min}^{-1}$ after $4-8$ weeks posttreatment $(p<0.001)$. The mean $( \pm S D)$ total follow-up time was $7.9 \pm 4.7$ months. Seventeen patients (22 lesions) underwent mid-term MRI. Of those, 9 (41\%) lesions had progressed at the mid-term follow-up. An increase in Ktrans after SRS was predictive of tumor progression (hazard ratio $=1.50$; $95 \%$ confidence interval: $1.16-1.70, p<0.001)$. An increase of $15 \%$ in Ktrans showed a $78 \%$ sensitivity and $85 \%$ specificity for prediction of progression at mid-term follow-up. Conclusion: SRS was associated with a reduction of Ktrans values of the cerebral metastases in the early post-treatment period. Furthermore, Ktrans variation as assessed using DCE MRI may be helpful to predict mid-term outcomes after SRS.

Descriptors: magnetic resonance spectroscopy; metastasis; brain; brain neoplasm; radiosurgery; capillary permeability. 


\section{INTRODUÇÃO}

Metástases encefálicas são os tumores intracranianos mais comuns em adultos e ocorrem em cerca de 10 a 30 \% de todos os pacientes com câncer (1). A radiocirurgia estereotática $(R C)$ é uma alternativa não invasiva à ressecção cirúrgica de metástases encefálicas, com eficácia confirmada por diversos estudos (1-3).

Os critérios radiológicos para avaliação da resposta precoce das metástases encefálicas à $R C$ ainda não foram muito bem estabelecidos. $O$ critério mais frequentemente utilizado para esta finalidade é o tamanho tumoral, o qual pode aumentar tanto como uma consequência da progressão da lesão como por alterações relacionadas com à radiação, tais como edema e inflamação (3-8). Huber et al.(5) relataram aumento volumétrico precoce e transitório em $12 \%$ de todas as metástases encefálicas tratadas com radiocirurgia, apesar de verificarem um índice de fracasso do tratamento de apenas $7 \%$. Desta forma, para se conseguir uma avaliação mais precisa, são necessários outros parâmetros, obtidos por técnicas de imagem avançadas, que possam detectar precocemente ou mesmo predizer o sucesso ou fracasso da terapêutica radiocirúrgica.

Dentre as técnicas avançadas de imagem, a técnica de permeabilidade por ressonância magnética $(\mathrm{RM})$ tem por finalidade estudar a integridade da barreira hematoencefálica $(9,10)$. Para isso, obtêm-se imagens repetidas ponderadas em T1 ao longo de vários minutos após a injeção de contraste paramagnético à base de gadolínio (11). A análise quantitativa desta sequência utiliza um modelo farmacocinético que pode estimar a extensão da acumulação de contraste em função do tempo: o coeficiente de transferência (transfer coefficient, Ktrans) (10,11). Este parâmetro é diretamente proporcional ao nível de permeabilidade da barreira hematoencefálica (9). Estudo recente demonstrou maior valor de Ktrans em tumores encefálicos primários de alto grau quando comparados aos de baixo grau (12). No entanto, o papel do Ktrans na avaliação 
de metástases encefálicas irradiadas ainda não foi investigado.

Diante do exposto acima, é possível que a análise do Ktrans contribua na avaliação da resposta das metástases encefálicas à radiocirurgia no período pós-tratamento precoce, auxiliando, portanto, na tomada de decisões terapêuticas e tratamentos alternativos mais rapidamente para os pacientes oncológicos.

\subsection{OBJETIVOS}

1. Avaliar o efeito da RC sobre a permeabilidade tumoral das metástases encefálicas, utilizando-se como parâmetro o Ktrans obtido pela técnica de permeabilidade por RM.

2. Avaliar a capacidade de medições Ktrans para prever a resposta do volume tumoral a médio prazo depois da RC. 


\section{REVISÃO DA LITERATURA}

\subsection{METÁSTASES ENCEFÁLICAS}

Metástases encefálicas constituem os tumores intracranianos mais comuns em adultos (13) e ocorrem em 10 a $30 \%$ dos pacientes oncológicos nestas faixas etárias (1). Os recentes avanços diagnósticos e terapêuticos vem promovendo aumento na incidência destas lesões. Smedby et al. demonstraram que a incidência anual de hospitalizações de pacientes portadores de metástase cerebral na Suécia dobrou entre 1987 e 2006. Neste mesmo estudo, os tumores primários que mais comumente metastatizaram para o cérebro foram pulmão, mama e câncer colorretal na mulher e pulmão, melanoma e câncer colorretal no homem (13).

As metástases encefálicas geralmente são múltiplas e distribuídas na junção córtico-subcortical, predominando nos hemisférios cerebrais $(80 \%)$, cerebelo (15\%) e tronco cerebral (5\%) (14). A RM é o melhor método de imagem para seu diagnóstico, pela maior resolução especial (14). Na RM, as metástases são frequentemente lesões arredondadas, com sinal intermediário ou alto nas sequências pesadas em T2, associadas a acentuado edema perilesional (14). Quando as lesões são sólidas, o realce costuma ser homogêneo e quando são císticas ou com componente necrótico o realce é periférico (14)(Figura 1). 


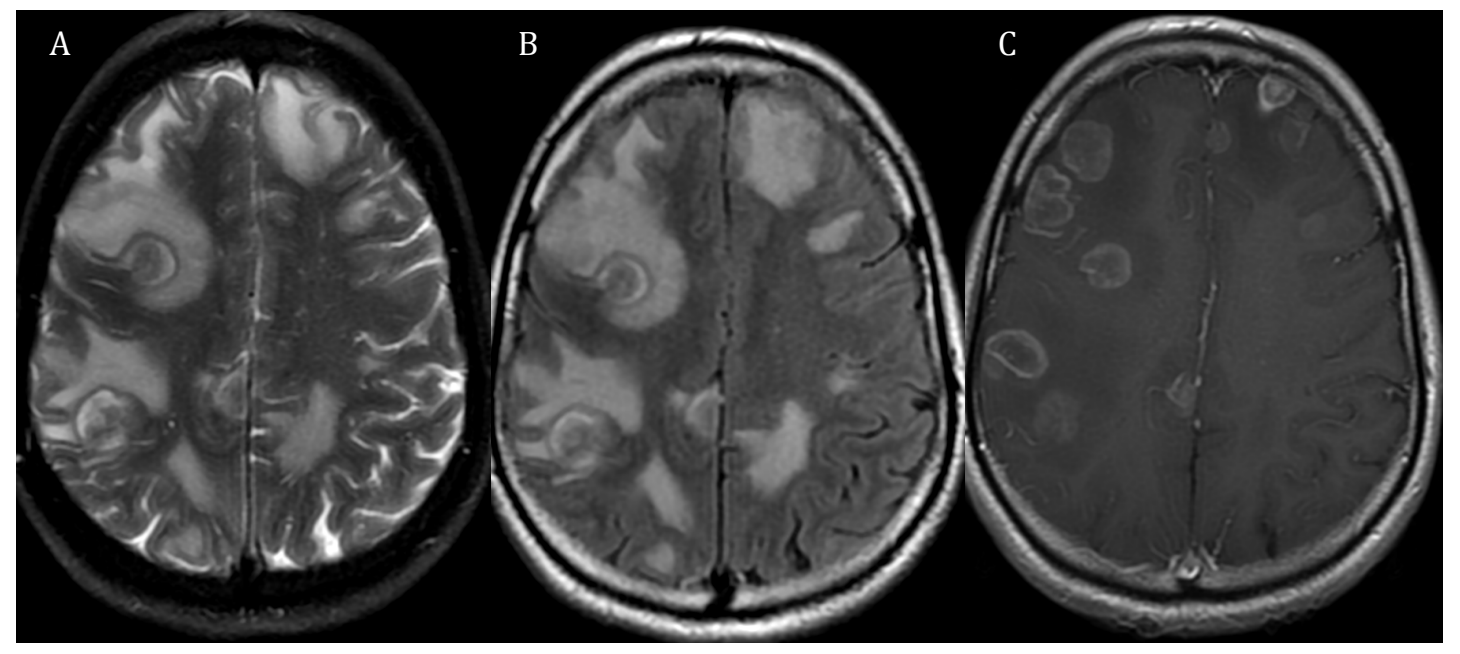

Figura 1 Metástases encefálicas em exame de ressonância magnética (RM). Imagens de RM obtidas em paciente do sexo masculino, 49 anos, com metástases de carcinoma de pequenas células do pulmão. $A, B$, e $C$ : imagens axiais respectivamente ponderadas em T2, FLAIR e T1 pós-contraste; múltiplas lesões nodulares distribuídas na transição córtico-subcortical de ambos os hemisférios cerebrais, margeadas por edema vasogênico

O manejo terapêutico dos pacientes com metástases encefálicas abrange a cirurgia, quimioterapia, radioterapia de cérebro total e a radiocirurgia estereotática. A escolha terapêutica depende da extensão da doença sistêmica, número, localização, tipo histológico e tamanho das metástases encefálicas, idade do paciente e performance status (KPS)(1).

\subsection{RADIOCIRURGIA ESTEREOTÁTICA NO TRATAMENTO DAS METÁSTASES ENCEFÁLICAS}

A radiocirurgia estereotática consiste em múltiplos feixes convergentes de radiação ionizante que se cruzam num alvo definido (2) (Figura 2). Ela 
permite que altas doses de radiação sejam direcionadas apenas ao tumor, determinando a morte das células neoplásicas, ao mesmo tempo que minimiza a dose para o parênquima cerebral normal adjacente e reduz os efeitos colaterais (2).

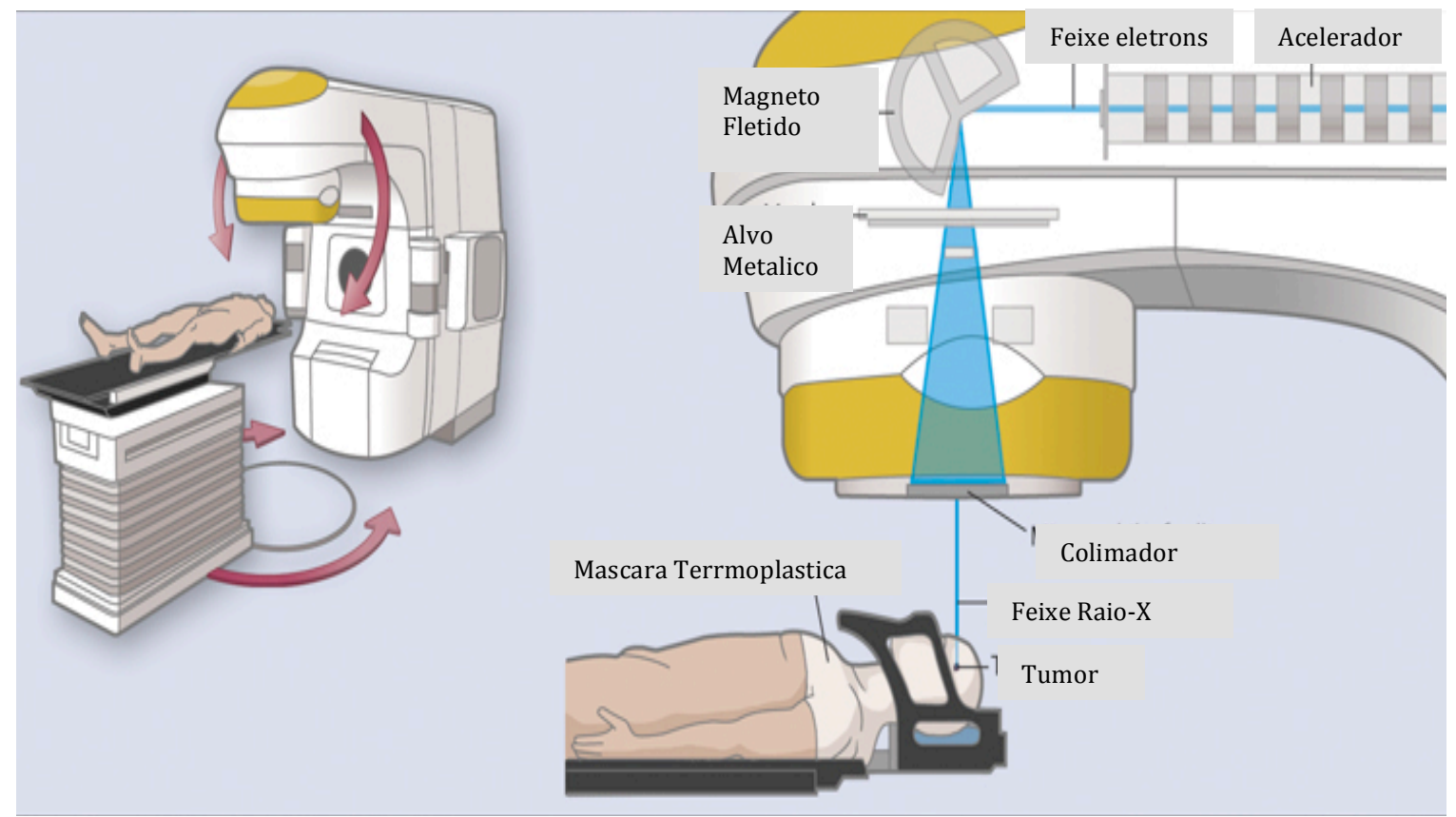

Figura 2. Esquema gráfico da técnica de radiocirurgia estereotática com acelerador linear. Múltiplos feixes de radiação ionizante convergindo para um alvo definido. Adaptado de Suh $\mathrm{JH}(2)$

Ensaios clínicos randomizados demonstraram que a radiocirugia estereotática combinada com a radioterapia de cérebro total aumentaram a sobrevida dos pacientes e o controle tumoral das metástases encefálicas quando comparados à radioterapia de cérebro total isolada (2). Resultados semelhantes foram obtidos em estudos retrospectivos quando se comparou a radiocirurgia estereotática com a cirurgia convencional (2).

Entretanto, a radiocirurgia estereotática apresenta eficácia limitada em certas situações. Entre elas, grande diâmetro tumoral e elevado número de 
lesões, pois nestes casos são necessárias altas doses de radiação que podem acarretar necrose ou deterioração neurológica $(1,2)$. Melhores resultados terapêuticos são obtidos quando os pacientes não apresentam ou estão sob controle da doença metastática sistêmica e quando apresentam status performance excelente (Karnofsky Performance Status [KPS] score de 90 a $100)(2,15)$.

A decisão terapêutica pela radiocirurgia baseia-se em fatores prognósticos pré-tratamento que podem impactar na sobrevida dos pacientes com metástases encefálicas $(16,17)$. Como citado anteriormente, KPS, idade, estado do tumor primário e metástase extracraniana, assim como o número de lesões encefálicas foram considerados fatores de prognóstico importantes (17). A síntese destes fatores geralmente norteiam a indicação de radiocirurgia, na forma de índices, já testados e validados na literatura. Os índices mais comumente utilizados são:

1) Análise de Particionamento Recursivo (originalmente do inglês, Recursive Partitioning Analysis - RPA), com três classes abrangendo combinações de quatro fatores (KPS, idade, estado do tumor primário e metástase extracraniana).

2) Pontuação Básica para Metástases Encefálicas (originalmente do inglês, Basic Score for Brain Metastases - BSBM), o qual é a soma de pontos (01) para três fatores prognósticos (KPS, estado do tumor primário e metástase extracraniana).

3) Índice de Pontuação para Radiocirurgia (originalmente do inglês, Score Index for Radiosurgery - SIR), consiste na soma de pontos (0-2) para cinco fatores (KPS, idade, estado da doença sistêmica, número das metástases encefálicas e volume da maior lesão)

4) Avaliação Prognóstica Graduada (originalmente do inglês, Graded Prognostic Assessment - GPA), baseia-se na soma de pontos (0, 0,5 e 1) para quatro fatores prognósticos (idade, KPS, número de metástases encefálicas e estado da doença sistêmica).

Todos os índices propostos apresentam possíveis limitações (17). Por 
exemplo, RPA e BSBM não incorporam o número de lesões (17). Por outro lado, SIR e GPA não consideram o estado do tumor primário (17). Desta forma, ainda não existe um consenso ou padrão-ouro na literatura. Assim, a utilização destes índices têm sido variável e dependente da preferência ou experiência de cada instituição.

Após a radiocirurgia, as complicações podem ser classificadas, segundo tempo de instalação, em: agudas (cefaleia, nauseas, crise epiléptica), quando occorem horas após a irradiação e estão associadas ao edema vasogênico; subagudas, quando ocorrem semanas a meses após o tratamento e são atribuídas a desmielinização transitória; tardias, quando ocorrem meses ou anos após o tratamento e estão relacionadas à gliose, às alterações vasculares e às disfunções neurais, culminando com a substituição do tecido encefálico normal por fibrose.(18)

\subsection{AVALIAÇÃO DAS METÁSTASES ENCEFÁLICAS TRATADAS COM RADIOCIRURGIA ATRAVÉS DA RESSONÂNCIA MAGNÉTICA}

Os efeitos biológicos relacionados à radiocirurgia das lesões encefálicas podem apresentar latência variável desde meses a anos, sendo tradicionalmente divididos em três fases temporais: inicial, com predomínio de edema, tanto lesional quanto no parênquima circunjacente, podendo inclusive haver aumento do volume da lesão; intermediária, com cavitação progressiva do tumor e proliferação capilar periférica, demonstrando clássico aspecto de contrastação anelar; e tardia, com necrose central da lesão e gliose residual marginal (19).

O seguimento das metástases encefálicas após a radiocirurgia estereotática geralmente é feito por exames de imagem seriados, sobretudo RM convencional, com a finalidade de avaliar principalmente as dimensões tumorais. 
Classicamente, as mudanças sequenciais dos tumores encefálicos que respondem ao tratamento, observadas na RM, são: aumento temporário, seguido por perda da impregnação pelo contraste no centro da lesão, parada de crescimento e, por fim, regressão ou mesmo desaparecimento tumoral. O realce periférico da lesão costuma ser inicialmente mais espesso, tornando-se mais discreto com o passar do tempo. O edema perilesional também é maior nos primeiros 2 a 6 meses e tende a regredir com o passar do tempo, até a instalação da gliose marginal (4) (Figura 3).

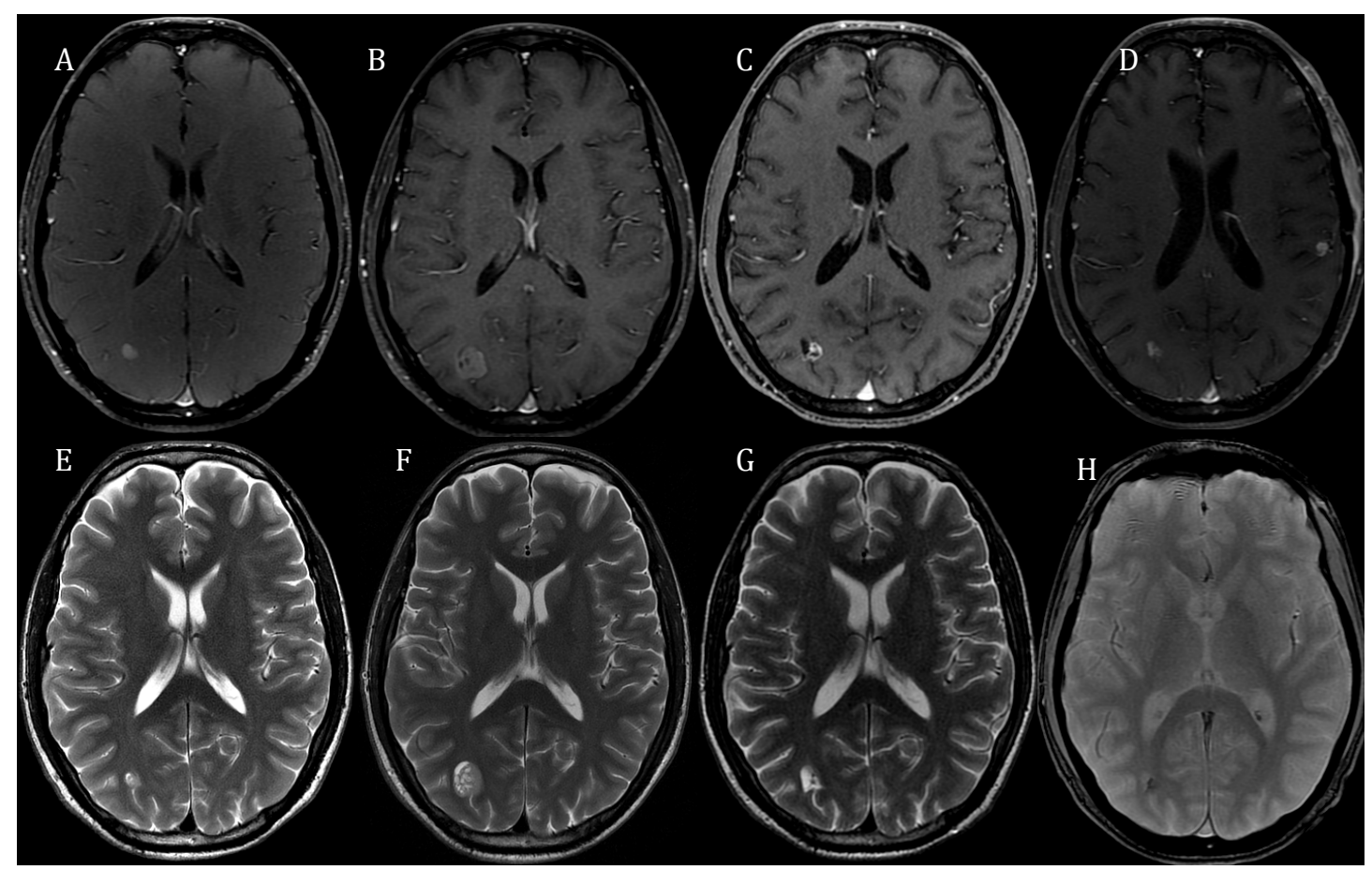

Figura 3 Evolução por imagem de metástase cerebral tratada por radiocirurgia. Imagens de RM obtidas em paciente do sexo masculino, 55 anos, com metástase pulmonar occipital direita tratada com radiocirurgia. $A, B, C$ e D: imagens axiais ponderadas em T1 pós-contraste; E, F e G: imagens axiais ponderadas em T2. H: imagem axial ponderada em T2*. Linha de base (A e E); fase inicial demonstrando aumento temporário (B e F); fase intermediária com parada de crescimento e perda da impregnação pelo contraste no centro da lesão (C e G), e, por fim, fase tardia com regressão tumoral calcificada, caracterizada por alto sinal na sequência T1 (D) e baixo sinal na sequência T2* 
(H). Observa-se ainda o aparecimento de novas lesões nodulares secundárias no parênquima do hemisfério cerebral esquerdo (D)

Dessa forma, a avaliação da resposta terapêutica por meio das dimensões tumorais pode demorar muito tempo. Além disso, alguns tumores aumentam ou permanecem com as mesmas dimensões após a radiocirurgia devido à necrose induzida pela radição ionizante, fenômeno conhecido como "pseudoprogressão", e não somente devido ao fracasso do tratamento $(7,20)$. Huber et al (5) relataram aumento volumétrico transitório em $12 \%$ de todas as metástases tratatadas com radiocirurgia, apesar de verificarem um índice de fracasso do tratamento de apenas $7 \%$. Por isso, técnicas de imagem avançadas que possam detectar precocemente ou mesmo predizer o sucesso ou fracasso da terapêutica radiocirúrgica tem sido investigadas (7).

As sequências de RM ponderadas em difusão constituem uma das técnicas recentemente utilizadas para a diferenciação entre progressão e pseudoprogressão tumoral após radiocirurgia (21) (Figura 4). Teoricamente, a difusão da água, mensurada pelo coeficiente aparente de difusão (CAD), apresenta correlação negativa com a celularidade e por isso se apresenta aumentada na necrose e reduzida no tumor viável(21) (Figura 4). Huang at al. $(21,22)$ demonstraram aumento dos valores de CAD no interior de metástases encefálicas após sucesso radioterapêutico. Outros estudos já haviam demonstrado resultados semelhantes (22). 


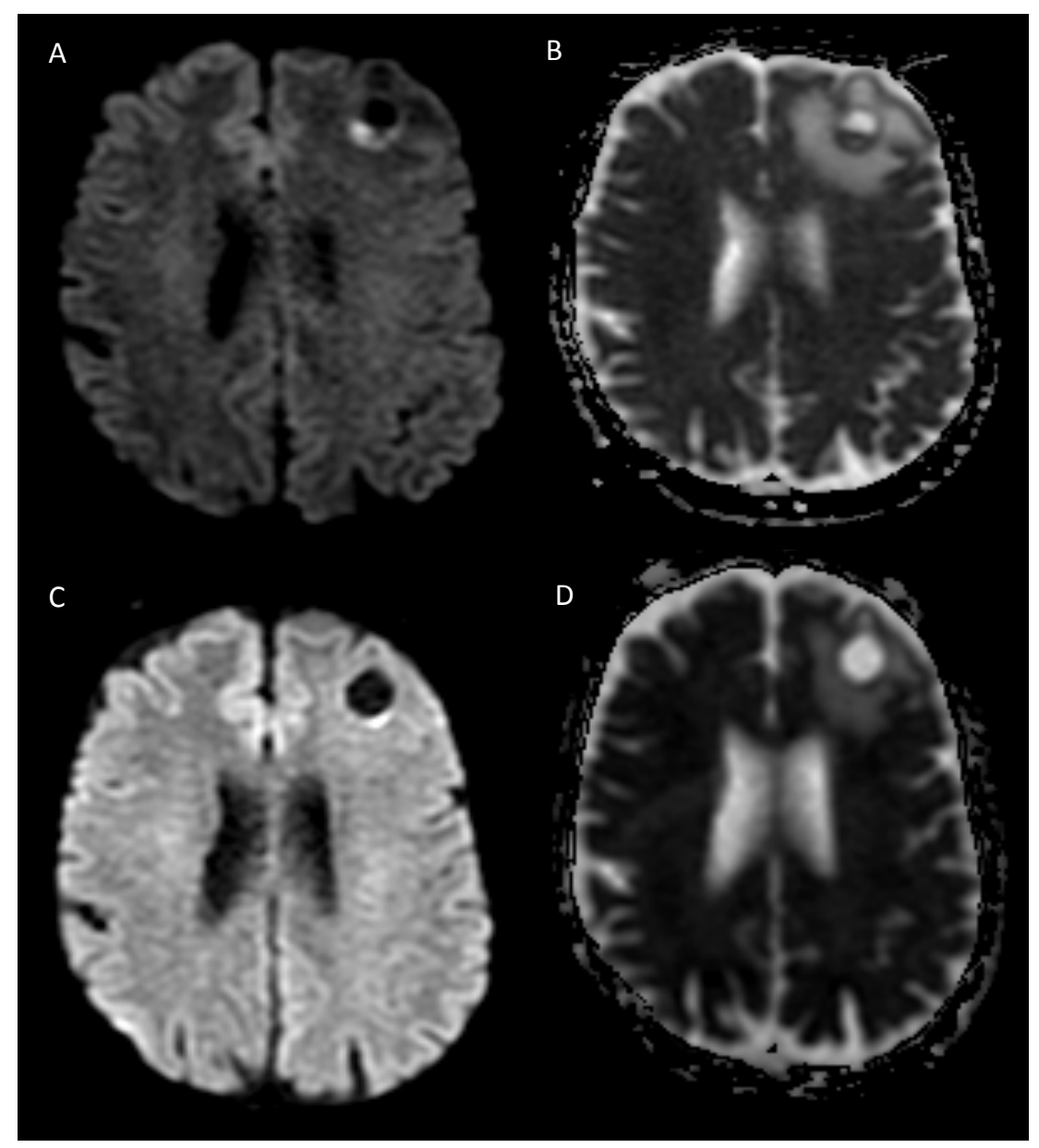

Figura 4. Metástase cerebral com boa resposta terapêutica após radicocirurgia. Imagens de RM obtidas em paciente do sexo feminino, 32 anos, com metástase de carcinoma de mama no parênquima frontal à esquerda, no momento do diagnóstico ( $A, B)$ e seis semanas $(C, D)$ após radiocirurgia. Houve redução do sinal intralesional na sequência difusão quando se compara o pré $(A)$ com o pós (C) tratamento, com respectivo aumento dos valores de difusão aparente $(B, D)$, indicando redução da celularidade

A técnica de perfusão por RM permite avaliar o suprimento sanguíneo capilar do tumor através da variação de sinal decorrente da passagem do contraste administrado por via endovenosa. Esta técnica também parece ser uma ferramenta valiosa na diferenciação entre necrose e recorrência tumoral após radiocirurgia (23) (Figura 5). Essig et al. (20) demonstraram que pacientes 
com metástases encefálicas tratadas com radiocirurgia estereotática apresentaram redução dos valores de volume sanguíneo cerebral (VSC) relativo e absoluto nos casos de resposta terapêutica ou doença estável, em contraposição ao aumento do VSC nos casos de não resposta. Entretanto, neste mesmo estudo, a avaliação do VSC pré-radiocirurgia não foi capaz de predizer se a metástase responderia ou não ao tratamento. Hoefnagels et al. (24), que também estudaram a perfusão de metástases encefálicas pós-radiocirurgia, sugeriram que valores do VSC relativo superiores a 1,85, em comparação ao córtex contralateral normal, praticamente excluem a possibilidade de radionecrose.

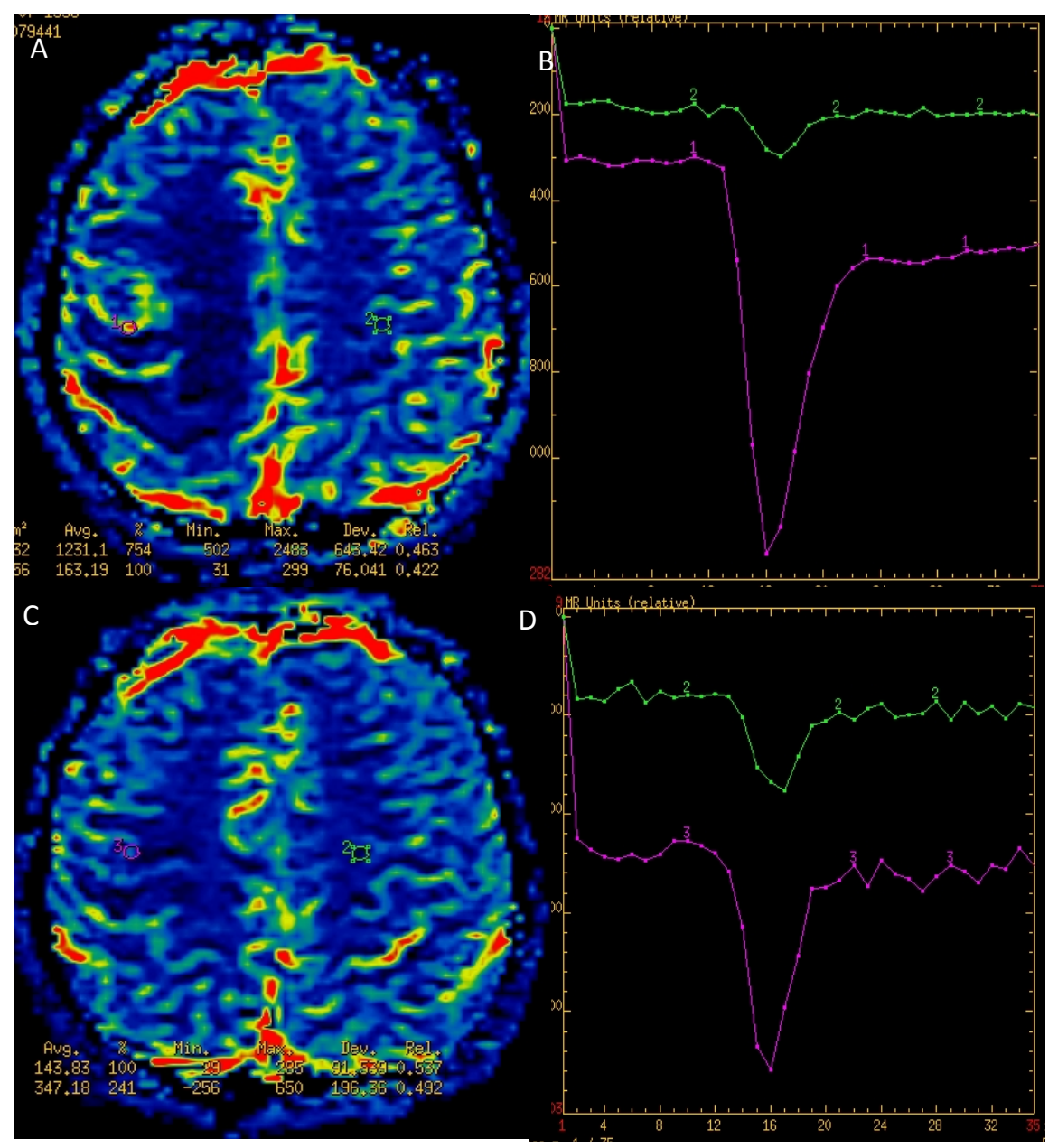

1. Lesão; 2. Parênquima cerebral contralateral. 
Figura 5. Metástase cerebral com boa resposta terapêutica após radicocirurgia. Imagens de RM obtidas em paciente do sexo masculino, 56 anos, com metástase de adenocarcinoma pulmonar no parênquima frontal à direita, no momento do diagnóstico (A, B) e cinco semanas $(C, D)$ após radiocirurgia. Os mapas de cores $(A, C)$ e gráficos $(B, D)$ do estudo de perfusão demontraram redução dos valores de volume sanguíneo cerebral após tratamento.

A técnica de "Arterial Spin Labeling" (ASL) foi desenvolvida com o objetivo de fornecer informações sobre a perfusão tumoral utilizando-se contraste endógeno (água), de forma não invasiva, sem necessidade de administração do gadolínio (25). Poucos estudos na literatura avaliaram a perfusão das mestástases encefálicas utilizando a sequência ASL. Em análise preliminar utilizando esta sequência, Weber et al. demonstraram evidências de que mudanças no fluxo sanguíneo cerebral relativo nas metástases encefálicas após radiocirurgia podem ser preditoras do desfecho clínico (26).

A espectroscopia por RM consiste numa técnica não invasiva que oferece informações metabólicas sobre a biologia tumoral. Pode ser considerada um método de baixa sensibilidade, porém, de alta especificidade no acompanhamento das metástases encefálicas após radiocirurgia. O principal metabóltito utilizado nestes casos é a colina (Co), um marcador metabólico de síntese de membranas celulares. Estudando pacientes com metástases encefálicas tratados com radiocirurgia estereotática, Huang et al.(27) sugeriram que relação maior que 1,2 entre a taxa de colina na lesão em relação ao parênquima normal (Co/nCo) praticamente exclui a possibilidade de radionecrose.

\subsection{AVALIAÇÃO DA PERMEABILIDADE TUMORAL POR RESSONÂNCIA MAGNÉTICA}




\subsubsection{Papel da Barreira Hematoencefálica nos Tumores Cerebrais}

A barreira hematoencefálica constitui uma barreira física de permeabilidade altamente seletiva que separa o sangue em circulação do fluido extracelular cerebral. É formada por células endoteliais capilares, pericitos e células astrogliais. Em geral, permite a passagem de substâncias com elevados coeficientes de partição octanol / água por difusão passiva. Além disso, algumas moléculas seletas, como glicose e aminoácidos, são transportadas de forma ativa ou facilitada para o cérebro. Por outro lado, neurotoxinas potenciais, mesmo com alto coeficiente de partição octanol / água, podem ser ativamente transportadas de volta ao sangue (10).

Nos tumores cerebrais de alto grau, incluindo as metástases, a barreira hematoencefálica está interrompida. Entre outros fatores, substâncias neoangiogênicas secretadas para o crescimento tumoral estão comprovadamente relacionadas à alteração da permeabilidade da barreira hematoencefálica. Os vasos neoformados pelo tumor costumam ter espaços entre as células endoteliais mais largos que os originalmente presentes nos vasos cerebrais normais (10).

A quebra da barreira hematoencefálica é geralmente identificada pelos métodos de imagem através do extravasamento do contraste administrado por via endovenosa para o espaço extravascular. Na RM, o agente de contraste geralmente utilizado é gadolínio quelato gadopentetato dimeglumina (Gd-DTPA), um traçador livremente difusível com um tamanho molecular de 550 Daltons. Uma vez no espaço extravascular, os píxeis de tecido com maiores concentrações do agente de contraste do que os seus vizinhos aparecem brilhantes em imagens de RM ponderadas em T1(11).

\subsubsection{Avaliação da permeabilidade da barreira hematoencefálica}


Permeabilidade descreve a facilidade que uma molécula apresenta para se deslocar entre dois compartimentos distintos, separados por uma barreira(9). No estudo da permeabilidade por meio da RM, a molécula de interesse é o agente de contraste (gadolínio); os dois ambientes distintos são os espaços intravascular e extravascular extracelular (EEE) e a barreira é a hematoencefálica (Figura 6).

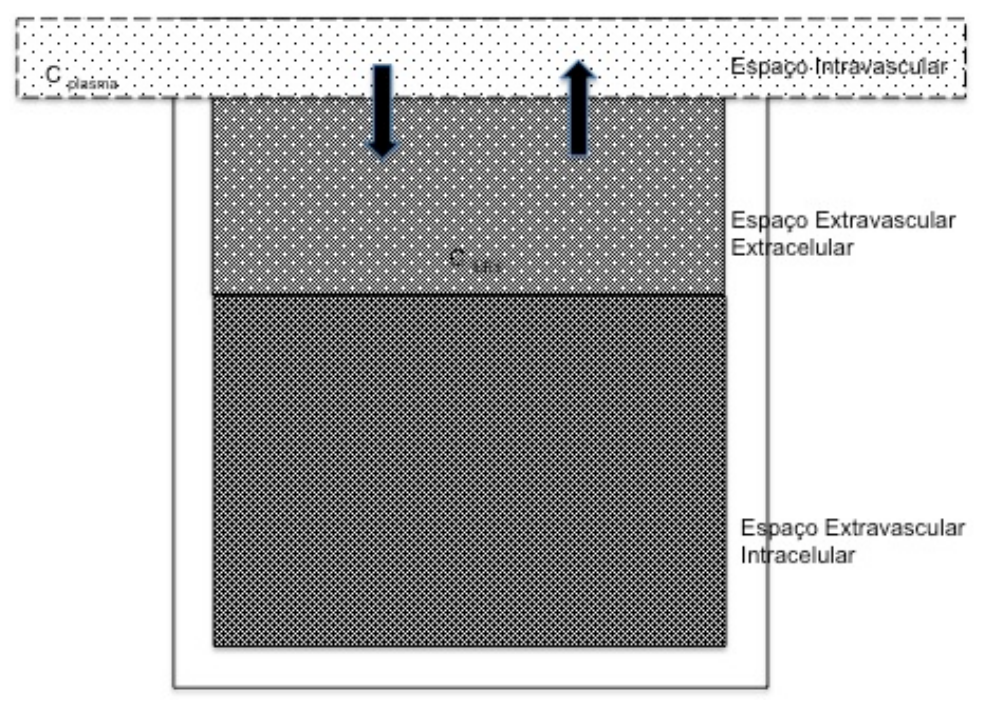

Figura 6. Esquema gráfico para avaliação da permeabilidade. As setas pretas indicam o fluxo de contraste entre os espaços intravascular e extravascular extracelular, a uma velocidade denominada Ktrans. As diferenças de relaxação são utilizadas para estimar as concentrações de contraste plasmáticas $\left(C_{\text {plasma }}\right)$ e do espaço extracelular extravascular (CEE). O contraste do espaço extravascular intracelular é excluído desta análise. Adaptado de Zaharchuk G (9)

Desta forma, o fluxo de um marcador pode ser definido pela área de superfície, gradiente de concentração e tempo (28):

fluxo do traçador $=P \times A \times M \times \Delta C$,

onde $\mathrm{P}$ é a permeabilidade (centímetro por segundo), A, a área de superfície por 
unidade de massa (centímetros quadrados por grama); $M$, a massa de tecido (g), e $\Delta C$ a diferença de concentração entre os dois compartimentos (milimole centímetro cúbico). Especificamente para a barreira hematoencefálica, a equação 1 pode ser escrita como:

$\frac{d \text { Ctecido }}{d t}=P \times A \times M \times($ Cplasma $-\mathrm{CEE})$,

onde $\mathrm{P}$ é a permeabilidade (centímetro por segundo), $\mathrm{A}$, a área de superfície por unidade de massa (centímetros quadrados por grama); $\mathrm{M}, \mathrm{a}$ massa de tecido ( $\mathrm{g}$ ), e ( $\left.\mathrm{C}_{\text {plasma- }} \mathrm{CEE}\right)$, a diferença de concentração entre os dois compartimentos (milimole centímetro cúbico).

Como não há uma maneira direta para separar permeabilidade e as alterações na superfície, geralmente, eles são agrupados como o "produto PA"(28). Assim, a Equação 2 pode ser escrita como:

$$
\frac{d \text { Ctecido }}{d t}=P A \rho\left(\text { Cplasma }-\frac{\text { Ctecido }}{\mathrm{V} e}\right)
$$

onde $\boldsymbol{\rho}$ é a densidade do cérebro. A concentração do espaço extracellular extravascular é definida pela proporção de " $\mathrm{C}_{\text {tecido" }}$ e a fração de volume do tecido " $\mathrm{V}_{\mathrm{e}}$.

Entretanto, na equação 3 , é necessário saber a concentracão de contraste plasmático no vaso capilar, o qual na verdade será estimado através da medida arterial. Assim, como é difícil saber a relação exata entre esses parâmetros, uma nova variável, o "coeficiente de transporte" (Ktrans), é usada no lugar do termo PAxp na equação 3(9):

$$
\frac{d \text { Ctecido }}{d t}=\mathrm{Ktrans}\left(\text { Cplasma }-\frac{\mathrm{Ctecido}}{\mathrm{V} e}\right)
$$

Em casos extremos, como nas neoplasias encefálicas, em que as concentrações de tranferência estão limitados pela taxa de chegada de contraste (isto é, limitada pelo fluxo sanguíneo cerebral [FSC]), pode-se assumir que: 
$\mathrm{K}_{\text {trans }}=F S C \times 1-H c t$

onde Hct corresponde ao hematócrito.

\subsubsection{Modelo Farmacocinético de Estimativa da Permeabilidade da Barreira Hematoencefálica}

A técnica de RM empregada na medida da permeabilidade baseia-se na obtenção de imagens repetidas ponderadas em T1 ao longo de vários minutos antes e após a injeção de contraste paramagnético à base de gadolíneo (11) (Figura 7). O curso temporal das concentrações de contraste no sangue e no tecido são determinados a partir das medidas de alteração de sinal. Posteriormente, as curvas resultantes são avaliadas por modelos farmacocinéticos para obtenção dos parâmetros de permeabilidade.

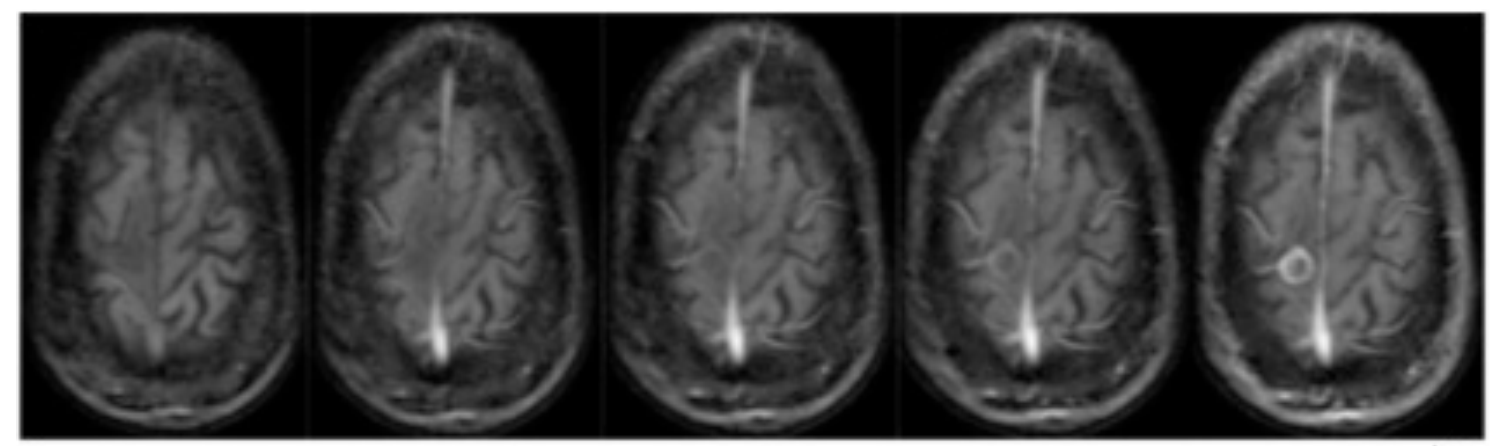

\section{Tempo}

Figura 7. Imagens de RM para avaliação da permeabilidade. Imagens de RM ponderadas em T1 demonstrando aumento gradual de realce em momentos subsequentes após a administração de contraste

O modelo estendido de Tofts-Kermode é o mais comumente utilizado 
(29). Neste modelo, a comparação entre imagens pré-contraste de base e o conhecimento da relaxação R1 inicial (inverso do T1) e TR da medição permite uma solução para a alteração da relação R1 ( $\Delta$ R1):

$\frac{S(t)}{\mathrm{S} 0}=\frac{1-\exp ([R 1-\Delta R 1] \times T R)}{1-\exp (R 1 \times T R)}$

assumindo-se que $\Delta \mathrm{R} 1$ é linearmente proporcional à concentração de contraste.

A alteração da relaxação ocorre em dois compartimentos, o plasma e o EEE, porque o agente de contraste é excluído do espaço intracelular. Assim, a concentração no tecido é a média ponderada destes dois:

$\operatorname{Ctecido}(\mathrm{t})=\operatorname{Vp} \operatorname{Cplasma}(\mathrm{t})+\operatorname{Ve} \operatorname{CEE}(\mathrm{t})$

onde Vp representa o volume plasmático (VSC.[1-Hct]). Como tanto o volume quanto a concentração plasmática (pelo menos vários minutos após a primeira passagem de contraste) são baixos, o termo plasmático pode ser ignorado. Então, a equação 4 pode ser re-escrita em termos de CEE:

$V e \times \frac{d C E E}{d t}=\operatorname{Ktrans}($ Cplasma $-C E E)$

o que pode ser resolvido com uma integral e inserida na equação 7 , ignorando as contribuições plasmáticas: 
Ctecido $(\mathrm{t})=\operatorname{Ktrans} \int_{0}^{t} \operatorname{Cplasma}(\tau) e^{-\operatorname{Ktrans}(t-\tau) \div V e} d \tau$

Essa equação é empregada para o ajuste da série temporal do sinal em cada voxel a fim de determinar Ktrans e ve, utilizando métodos não-lineares de quadrados mínimos (9). 


\section{MÉTODOS}

Este estudo observacional prospectivo foi realizado no Setor de Ressonância Magnética do Instituto de Radiologia (INRAD) do Hospital das Clínicas da Faculdade de Medicina da Universidade de São Paulo (HCFMUSP) e do Instituto do Câncer do Estado de São Paulo (ICESP). Seu protocolo (n 0520/10) foi aprovado pela Comissão de Ética para Análise de Projetos de Pesquisa - CAPPesq da Diretoria Clínica do Hospital das Clínicas e da Faculdade de Medicina da Universidade de São Paulo (Anexo A). Os participantes foram informados sobre os objetivos e procedimentos do estudo e assinaram o termo de consentimento livre e esclarecido.

\subsection{DESENHO DO ESTUDO}

Os participantes foram submetidos à RM com técnica de permeabilidade antes da realização da radiocirurgia estereotática, nomeado como linha de base, e 4 a 8 semanas após o tratamento, nomeado como seguimento precoce. Nestas ocasiões, foram mensurados os valores do coeficiente de transferência (Ktrans).

Paralelamente, foram também calculados os volumes tumorais na linha de base e no seguimento precoce, assim como num período mais tardio, após 16 semanas, nomeado como seguimento a médio prazo.

Um algoritmo que sintetiza o desenho do estudo está disponível na Figura 8. 


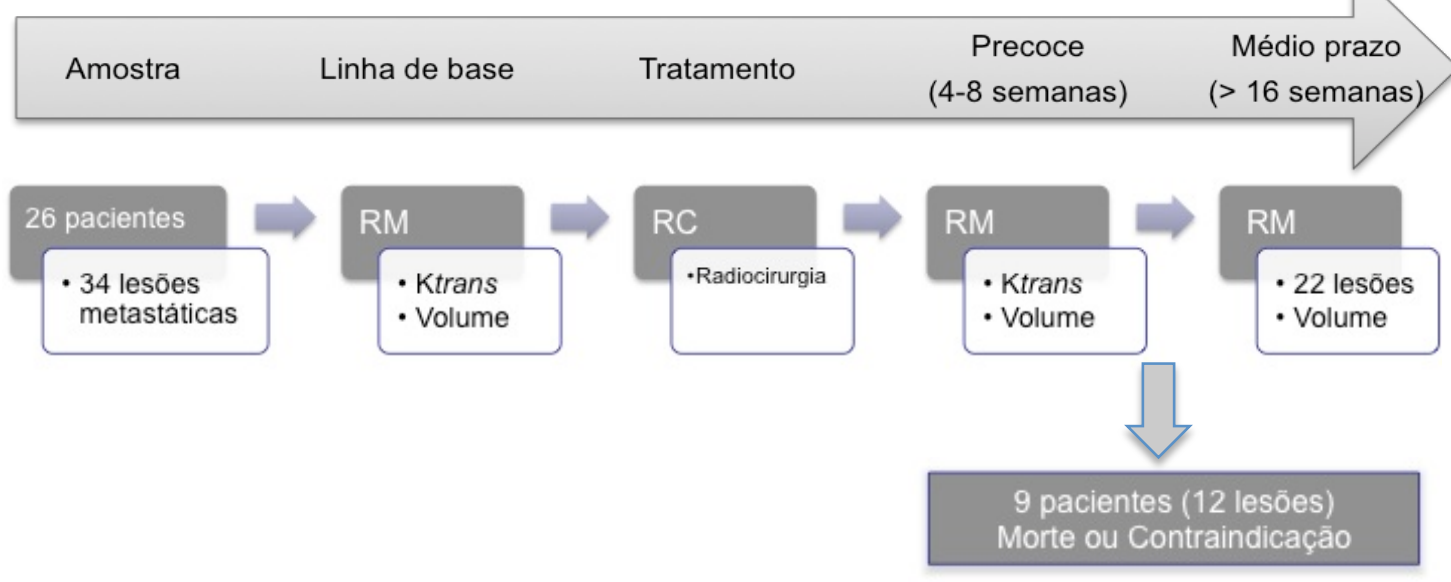

Figura 8. Algoritmo descrevendo desenho do estudo. Vinte e seis pacientes totalizando 34 metástases encefálicas foram submetidos a RM com a técnica de permeabilidade antes (linha de base) e 4 a 8 semanas (seguimento precoce) após radiocirurgia. Dos 26 pacientes, dezessete, com 22 lesões metastáticas, foram submetidos ainda a RM convencional pelo menos 16 semanas após 0 tratamento (seguimento médio prazo). Foram comparados os valores de Ktrans na linha de base e no seguimento precoce, assim como o volume tumoral entre a linha de base e o segmento a médio prazo

\subsection{PARTICIPANTES}

\subsubsection{Recrutamento}

Nesta amostragem por conveniência, os pacientes consecutivos que tinham idade igual ou superior a 18 anos, portadores de metástases encefálicas e acompanhados nos setores de radioterapia do InRad e do ICESP foram 
incluídos no estudo.

\subsubsection{Dados Demográficos}

Foram coletados no prontuário dados referentes à idade, sexo, raça, sítio primário da neoplasia, classificação histológica do tumor primário, estadiamento oncológico, história de tratamentos quimioterápico e/ou radioterápico pregressos, co-morbidades sistêmicas e uso de medicações.

\subsubsection{Seleção}

\subsubsection{Critérios de Inclusão}

Os seguintes critérios de inclusão foram adotados para selecionar os participantes:

- Idade igual ou superior a 18 anos;

- Diagnóstico de metástase cerebral caracterizada em exame de Ressonância Magnética;

- Indicação clínica de radiocirurgia estereotática baseada nos seguintes critérios: idade; KPS; extensão da doença sistêmica; número, dimensões e 
localização das metástases encefálicas; histologia do tumor primário. Foi utilizado algoritmo previamente publicado na literatura (Índice de Pontuação para Radiocirurgia) (16), com ponto de corte maior ou igual a 4.

\subsubsection{Critérios de Exclusão}

Foram excluídos do estudo os pacientes que apresentassem quaisquer dos critérios abaixo:

- Cirurgia convencional pregressa no sítio da metástase a ser tratada por radiocirurgia;

- Contra-indicação absoluta à realização de RM;

- Contra-indicação absoluta à utilização de contraste paramagnético por via endovenosa;

- Lesão metastática cerebral de dimensões reduzidas (mínimo de 50 voxels).

\subsection{EXAMES REALIZADOS APÓS A SELEÇÃO}

Foram realizados exames de RM de crânio em aparelho de 1,5 Tesla (General Electric Medical Systems, Waukesha, WI) antes da realização da radiocirurgia estereotática e 4 a 8 semanas após o tratamento.

A sequência de permeabilidade foi adicionada ao protocolo habitual, utilizando-se aquisição gradiente-eco ponderada em T1, com técnica steady state e os seguintes parâmetros: campo de visão $=256 \mathrm{~mm}$, espessura $=7,0$ 
mm, matriz de 192 x 192, flip angle: 14; número de excitações (Nex) = 0,67 e tempo de eco $(T E) /$ tempo de repetição $(T R)=5,9 / 1,9$ ms. Cinquenta fases dinâmicas foram obtidas com uma intervalo temporal amostral de $5,56 \mathrm{~s}$ e um tempo total de $6,5 \mathrm{~min}$. A injeção de $0,05 \mathrm{mmol} / \mathrm{Kg}$ do agente de contraste gadolíneo (Magnevist; Schering, Alemanha ou Dotarem; Guerbet, França) foi realizada após o quinto pacote de imagens dinâmicas, com fluxo de 3-4 mL/s.

\subsection{TRATAMENTO RADIOTERÁPICO}

Todos os participantes receberam uma única dose de radiocirurgia para cada lesão metastática cerebral, utilizando-se equipamento acelerador linear de partículas $^{1}$, com o uso de um sistema computadorizado de planejamento ${ }^{2}$. Cinco participantes haviam recebido previamente radioterapia de cérebro total com dose média de 3.000 cGy dividida em 10 frações. De acordo com o protocolo da instituição, nenhum participante recebeu corticoterapia para prevenção de edema cerebral.

\subsection{SEGUIMENTO DOS PARTICIPANTES}

Os participantes foram acompanhados segundo a rotina das instituições, que consiste em exame clínico e RM de crânio 4 a 8 semanas após a realização da radiocirurgia e, subsequentemente, a cada 2 a 3 meses. Neste período, foram avaliados os sintomas apresentados após o tratamento radioterápico assim como o desfecho clínico.

\footnotetext{
${ }^{1}$ Varian de $6 \mathrm{MV}^{\circledR}$ - Varian Medical Systems (VMS), Inc, Palo Alto, California, EUA

${ }^{2}$ Brain Scan, Image Fusion 5.3.1 - BrainLab, Hunique, Alemanha
} 


\subsection{ANÁLISE DAS IMAGENS}

A análise das imagens de permeabilidade foi realizada utilizando-se $o$ pacote comercial NordiclCE versão 3.3.12 (Nordic Imaging Lab: NIL, Bergen, Noruega). Este pacote aplica o modelo cinético de dois compartimentos, previamente descrito para a estimativa de Ktrans(29). A função de entrada arterial foi determinada com a ferramenta de detecção automática após a correção de artefatos de movimento. O valor T1 basal (pré-contraste) foi fixado a um valor específico para todos os voxels. Os mesmos parâmetros de processamento foram utilizados para os exames antes e após o tratamento.

Mapas paramétricos foram utilizados para medir o valor de Ktrans nas regiões de interesse (ROI) dos tumores. O posicionamento das $\mathrm{ROI}$ nas imagens T1 pós-contraste foi realizado por uma única neurorradiologista, a qual não sabia a data do exame. As ROI tinham um tamanho mínimo de 50 voxels e incluiam tanto a área de realce pelo contraste quanto o centro necrótico tumoral. $O$ tecido necrótico foi incluído a fim de garantir a resolução mínima, uma vez que muitas lesões eram de tamanho muito reduzido.

As medições do Ktrans foram determinadas em todos os cortes transversos em que havia lesão. Foram avaliadas em dois momentos do estudo: na linha de base (antes da RC) e após início do tratamento (4 a 8 semanas). Os valores mais elevados (máximo) foram utilizados para análise. A escolha pelos valores máximos teve por finalidade minimizar o risco de subestimar a permeabilidade das possíveis áreas tumorais viáveis.

A razão de Ktrans foi definida como a diferença entre o valor medido no seguimento precoce (4-8 semanas pós-tratamento) e na linha de base (pré-RC), dividida pela linha de base, conforme equação (10).

$$
\text { Razão Ktrans }=\text { Ktrans pos }- \text { Ktrans }(\text { pre }) / \text { Ktrans }(\text { pre })
$$


Desta forma, uma razão de Ktrans negativa indicaria redução da permeabilidade, enquanto que uma razão positiva representaria um aumento da permeabilidade da lesão.

Para a estimativa do volume tumoral, a mesma neurorradiologista que desconhecia os momentos de estudo mediu os maiores diâmetros do tumor em três planos ortogonais (ântero-posterior, D1; latero-lateral, D2, e supero-inferior, d3), utilizando imagens volumétricas ponderadas em T1 pós-contraste, como habitualmente utilizado pelo serviço de radioterapia da instituição. Os volumes do tumor foram subsequentemente calculados para cada um dos três pontos de tempo do estudo: linha de base (antes da RC); seguimento precoce (4 a 8 semanas); e seguimento a médio prazo (> 16 semanas). Para o cálculo do volume tumoral, utilizou-se a seguinte equação (11):

$$
\text { Volume }=\frac{4}{3} \times \pi \times\left(\frac{\mathrm{d} 1}{2} \times \frac{d 2}{2} \times \frac{d 3}{2}\right)
$$

A taxa de crescimento tumoral foi definida como a diferença entre o volume do tumor a médio prazo (> 16 semanas) e o volume de tumor na linha de base, dividida pelo tempo de seguimento após a RC (em dias), conforme equação (12).

Taxa Crescimento Tumoral: $\Delta$ volume tumoral $(\mathrm{cm}) / \Delta t$ (dias)

O resultado a médio prazo foi também classificado categoricamente através da comparação do volume do tumor após 16 semanas em relação à linha de base: reduçãoo volumétrica tumoral (redução no volume do tumor > $25 \%$ ), estabilidade volumétrica tumoral (redução no volume do tumor $<25 \%$ ou um aumento no volume de tumor $<25 \%$ ) e aumento / progressão volumétrica tumoral (aumento no volume do tumor $>25 \%$ ). 


\subsection{ANÁLISE ESTATÍSTICA}

A análise estatística foi realizada utilizando-se o pacote estatístico STATA versão 12.0 (StataCorp LP). Foi adotado erro $\alpha$ de 0,05 para as análises estatísticas inferenciais.

\subsubsection{Cálculo do Tamanho Amostral}

O tamanho amostral mínimo calculado para obter um poder de $90 \%$ e considerando erro $\alpha$ de 0,05 para detectar uma diferença de 0,1 na variação de Ktrans entre os dois cortes temporais do estudo (linha de base e seguimento precoce) foi de 22, considerando desvio-padrão (DP) de 0,1.

\subsubsection{Estatística Descritiva}

Para a análise estatística descritiva, foram calculados média, mediana, DP, quartis inferior e superior, mínimo e máximo das variáveis numéricas contínuas. Foram calculadas as frequências absolutas e relativas das variáveis categóricas. 


\subsubsection{Estatística Inferencial}

Para a análise estatística inferencial, levando-se em consideração a correlação entre diferentes metástases em um mesmo indivíduo, utilizou-se um modelo de Equação de Estimativa Generalizada com erro-padrão robusto para comparação das médias dos valores de Ktrans.

Como o volume tumoral não apresentou distribuição normal, a sua comparação entre os diferentes cortes temporais foi realizada através do teste de Wilcoxon.

A relação entre Ktrans e volume do tumor foi avaliada usando 0 coeficiente de correlação de Spearman considerando-se a razão do Ktrans e a taxa de crescimento do tumor como variáveis.

As razões de risco para associação entre Ktrans e progressão do tumor a médio prazo foram obtidas utilizando o modelo proporcional de Cox. Para esta análise, as categorias "remissão do tumor" e "doença estável" foram agrupadas como "controle local." Outras variáveis analisadas como potenciais fatores preditivos foram dose de radiação, tumor primário e gênero. Como testamos um total de quatro potenciais fatores preditivos, o nível de significância para as comparações múltiplas foi controlada pela aplicação da correção de Bonferroni e $P \leq 0,01$ foi considerado estatisticamente significativo para esta análise.

A análise de sobrevida de Kaplan-Meier e o teste de log-rank foram utilizados para avaliar se um aumento do Ktrans após RC foi associado com a progressão do tumor. A sensibilidade e especificidade da razão Ktrans para prever a resposta ao tratamento foram calculadas através da Curva Característica de Operação do Receptor (Curva ROC). 


\section{RESULTADOS}

Durante o período de fevereiro de 2011 a novembro de 2012, 34 pacientes com metástases tumorais em tratamento no ambulatório de radioterapia do INRAD e ICESP foram recrutados para este estudo. Oito pacientes foram excluídos: sete óbitos e uma evolução para insuficiência renal no período compreendido entre o tratamento radioterápico e a realização do exame de seguimento (após 4 a 8 semanas). Dentre os 26 pacientes elegíveis, havia um total de 39 metástases encefálicas. Cinco destas metástases foram excluídas devido às diminutas dimensões. Ao final, 34 lesões metástaticas encefálicas foram avaliadas (Anexo B).

\subsection{DADOS DEMOGRÁFICOS E CLÍNICOS}

Os dados demográficos e clínicos dos participantes encontram-se na Tabela 1.

Do total de 26 participantes, nove deles evoluíram para óbito ou insuficiência renal ou implantaram aparelhos eletrônicos que contraindicavam a realização de RM durante o seguimento. Os dezessete participantes restantes apresentaram um total de 22 lesões, as quais foram avaliadas por RM convencional após no mínimo 16 semanas da RC. O período de seguimento médio (DP) foi de 7,9 (4,7) meses (mediana: 6,5; extensão: 1,3 - 20,3 meses). 
Tabela 1: Dados demográficos e clínicos dos participantes

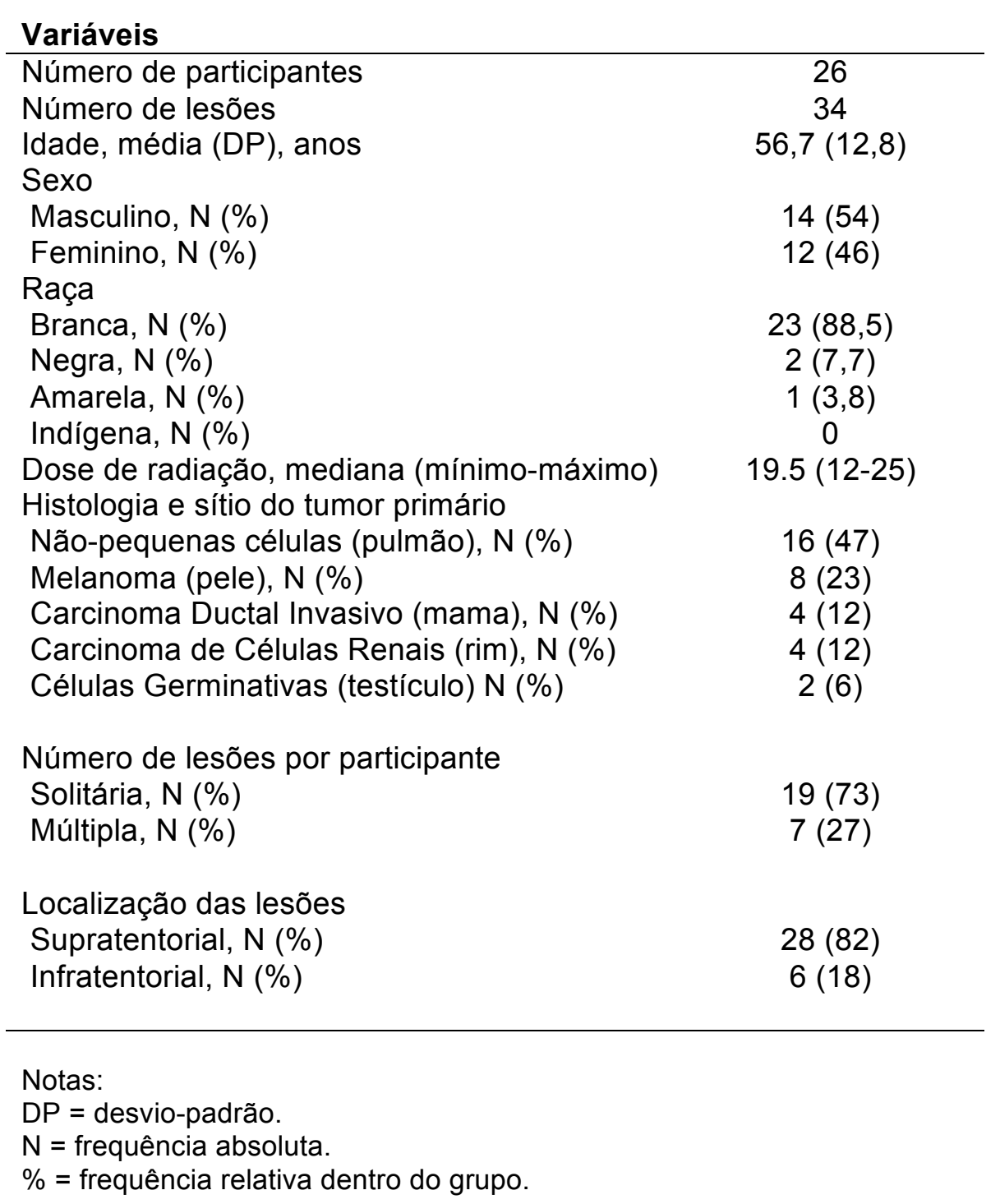




\subsection{AVALIAÇÃO DAS MEDIDAS DE KTRANS E VOLUME TUMORAL}

As medidas de Ktrans das lesões metastáticas apresentaram uma redução significativa após o tratamento com $\mathrm{RC}$. A média $( \pm \mathrm{DP})$ dos valores de Ktrans foi de 0,13 $\pm 0,11 \mathrm{~min}^{-1}$ na linha de base e 0,08 $\pm 0,07 \min ^{-1}$ no seguimento precoce pós-tratamento $(p<0,001)$.

Em relação ao volume tumoral, embora tenha havido uma tendência para a sua redução ao longo do acompanhamento, isso não foi estatisticamente significante.

O curso temporal das medidas de Ktrans e volume tumoral das lesões tumorais metastáticas encontra-se descrito na Tabela 2.

Tabela 2: Descrição do curso temporal das medidas de Ktrans e volume tumoral das lesões tumorais metastáticas

\begin{tabular}{lccc}
\hline Parâmetros & Linha de base & $\begin{array}{c}\text { Seguimento } \\
\text { Precoce }\end{array}$ & $\begin{array}{c}\text { Seguimento } \\
\text { Médio Prazo }\end{array}$ \\
\hline $\begin{array}{l}\text { Máximo Ktrans, } \\
\text { média (DP), min }\end{array}$ & $0,13(0,11)$ & $0,08(0,07)^{\dagger}$ & NA \\
$\begin{array}{l}\text { Volume tumoral, } \\
\text { mediana (Q1; Q3), } \\
\mathrm{cm}^{3}\end{array}$ & $0,65(0,3 ; 1,4)$ & $0,5(0,09 ; 1,7)$ & $0,27(0,03 ; 1,8)$ \\
\hline
\end{tabular}

Notas:

$D P=$ Desvio Padrão

NA: Não se aplica

Q1: Quartil inferior

Q3: Quartil superior

${ }^{\dagger}=\mathrm{p}<0,001$

A razão de Ktrans apresentou média $( \pm \mathrm{DP})$ de 0,18 \pm 2,02 e mediana (Q1; Q3) de $-0,35(-0,61 ; 0,15)$. A taxa de crescimento tumoral apresentou média $( \pm \mathrm{DP})$ de $0,016 \mathrm{~cm}^{3} / \mathrm{dia} \pm 0,05$ e mediana $(\mathrm{Q} 1 ; \mathrm{Q} 3)$ de $-0,0004 \mathrm{~cm}^{3} / \mathrm{dia}(-0,001$; $0,004)$. Houve uma correlação positiva estatisticamente significante entre a razão de Ktrans e a taxa de crescimento tumoral (coeficiente de Spearman $=0,58, p=$ 
0,005).

Observou-se ainda uma correlação negativa entre os valores de Ktrans pré-tratamento e a taxa de crescimento tumoral (coeficiente de Spearman =0,5, $p=0,02)$.

Os testes de correlação entre as medidas de Ktrans e volume tumoral estão descritos na Tabela 3.

Tabela 3: Correlação entre as medidas de Ktrans e de volume tumoral

\begin{tabular}{|c|c|c|c|c|c|c|c|c|}
\hline & \multicolumn{2}{|c|}{$\begin{array}{l}\text { Volume tumoral } \\
\text { (linha de base) }\end{array}$} & \multicolumn{2}{|c|}{$\begin{array}{l}\text { Volume } \\
\text { tumoral } \\
\text { (precoce) }\end{array}$} & \multicolumn{2}{|c|}{$\begin{array}{c}\text { Volume } \\
\text { tumoral } \\
\text { (médio prazo) }\end{array}$} & \multicolumn{2}{|c|}{$\begin{array}{c}\text { Taxa de } \\
\text { Crescimento } \\
\text { tumoral }\end{array}$} \\
\hline & $r$ & $P$ & $r$ & $P$ & $r$ & $\mathrm{P}$ & $r$ & $P$ \\
\hline $\begin{array}{l}\text { Ktrans } \\
\text { (Linha de Base) }\end{array}$ & 0,07 & 0,68 & $-0,08$ & 0,67 & $-0,26$ & 0,24 & $-0,50^{*}$ & 0,02 \\
\hline $\begin{array}{l}\text { Ktrans } \\
\text { (Seguimento } \\
\text { precoce) }\end{array}$ & 0,12 & 0,49 & 0,04 & 0,82 & 0,13 & 0,57 & 0,06 & 0,78 \\
\hline Razão de Ktrans & $-0,14$ & 0,42 & $-0,01$ & 0,96 & 0,36 & 0,10 & $0,58^{*}$ & 0,005 \\
\hline
\end{tabular}

\subsection{AVALIAÇÃO DA RESPOSTA VOLUMÉTRICA TUMORAL A MÉDIO PRAZO}

Dos 17 pacientes (22 lesões) que foram submetidos a RM a médio prazo (> 16 semanas), 11 (50\%) lesões apresentaram redução volumétrica tumoral, 2 (9\%) lesões foram classificadas como estáveis, e 9 (41\%) lesões apresentaram aumento do volume tumoral. 


\subsection{RELAÇÃO ENTRE AS ALTERAÇÕES DAS MEDIDAS DE KTRANS E A RESPOSTA VOLUMÉTRICA TUMORAL A MÉDIO PRAZO}

Um aumento na razão de Ktrans foi significativamente associado com a progressão volumétrica da lesão (Figura 9). Cada unidade de aumento na razão de Ktrans após RC foi associada com um risco acrescido de $50 \%$ de progressão volumétrica do tumor (taxa de risco: 1,50, 95\% intervalo de confiança 95\%: 1,16 $1,70, P<0,001)$. Não houve associação significativa entre a dose de radiação, histologia do tumor primário, idade ou gênero com a resposta do volume tumoral a médio prazo.

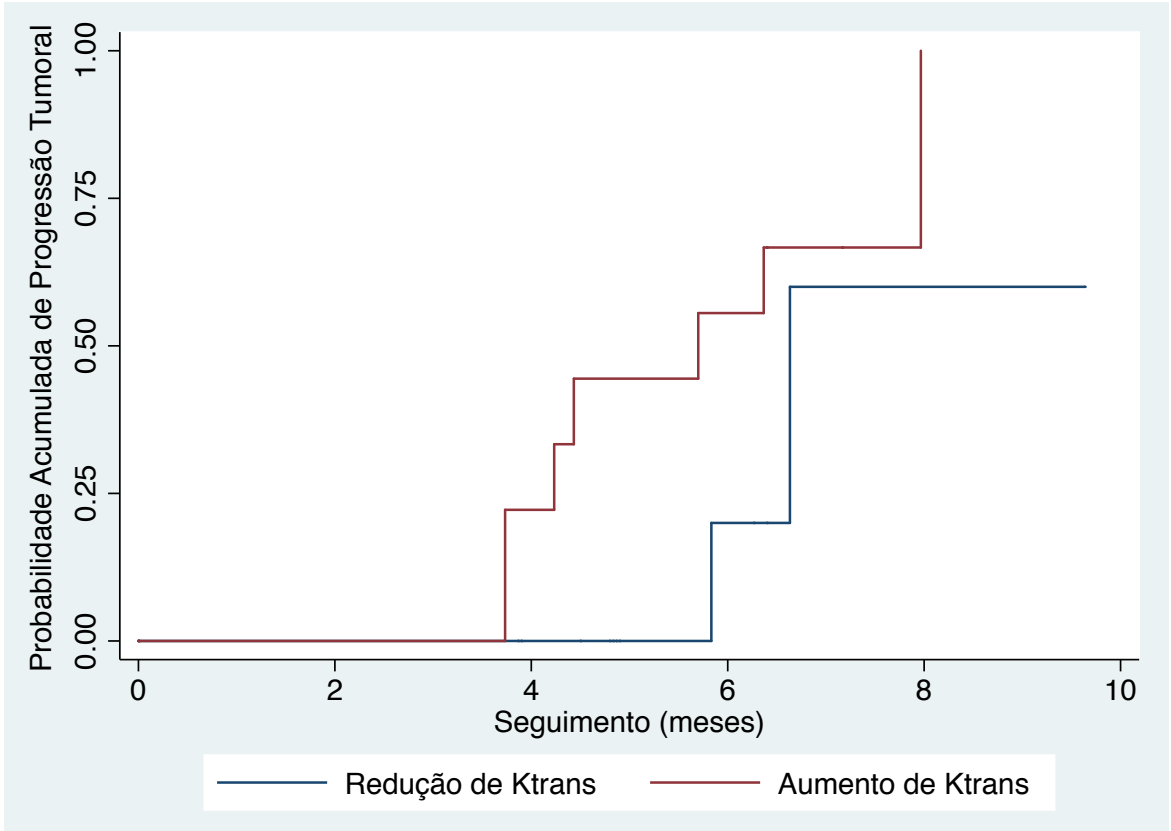

Figura 9. Curvas estimativas de falha de Kaplan-Meier avaliando a resposta volumétrica tumoral a médio prazo, comparando-se as lesões com aumento do Ktrans versus aquelas com diminuição do Ktrans após radiocirurgia estereotática

A curva ROC da razão de Ktrans para prever a resposta volumétrica tumoral a médio prazo é ilustrada na Figura 10. A razão de Ktrans apresentou 
uma área sob a curva ROC de 0,86, com uma sensibilidade de $78 \%$ e uma especificidade de $85 \%$ quando foi utilizado um ponto de corte de 0,15 (aumento de 15\%). As Figuras 11 e 12 ilustram casos de redução e progressão volumétrica da lesão, respectivamente.

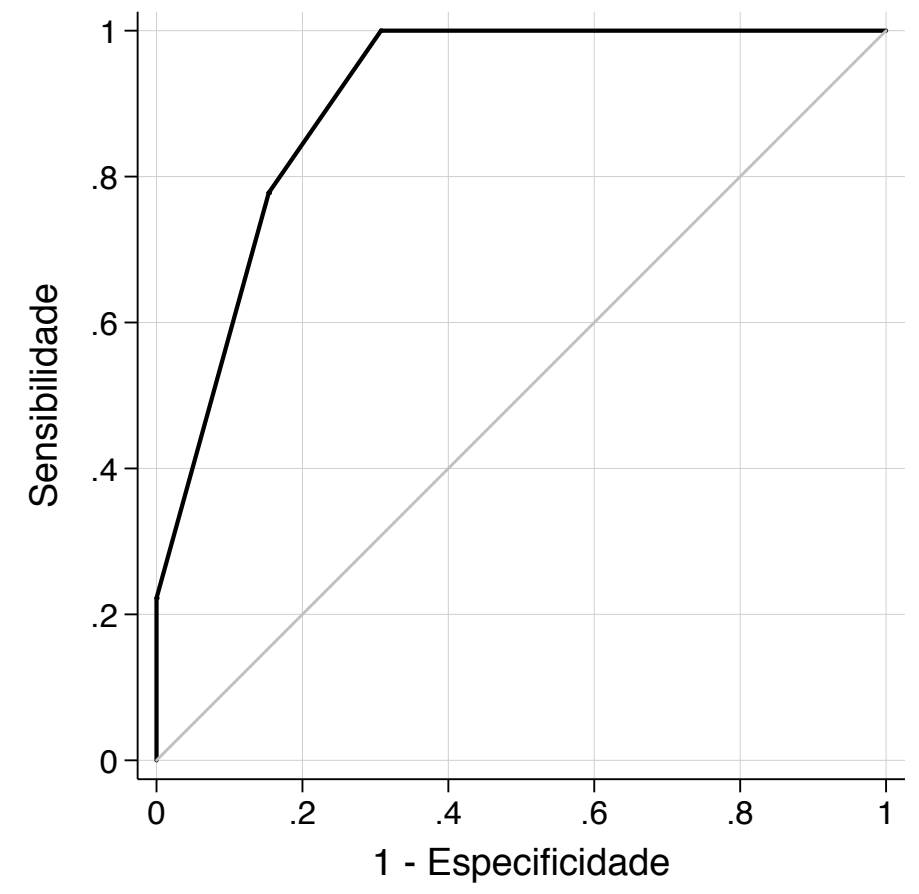

Figura 10. Curva ROC da razão de Ktrans para a previsão da resposta volumétrica tumoral a médio prazo 


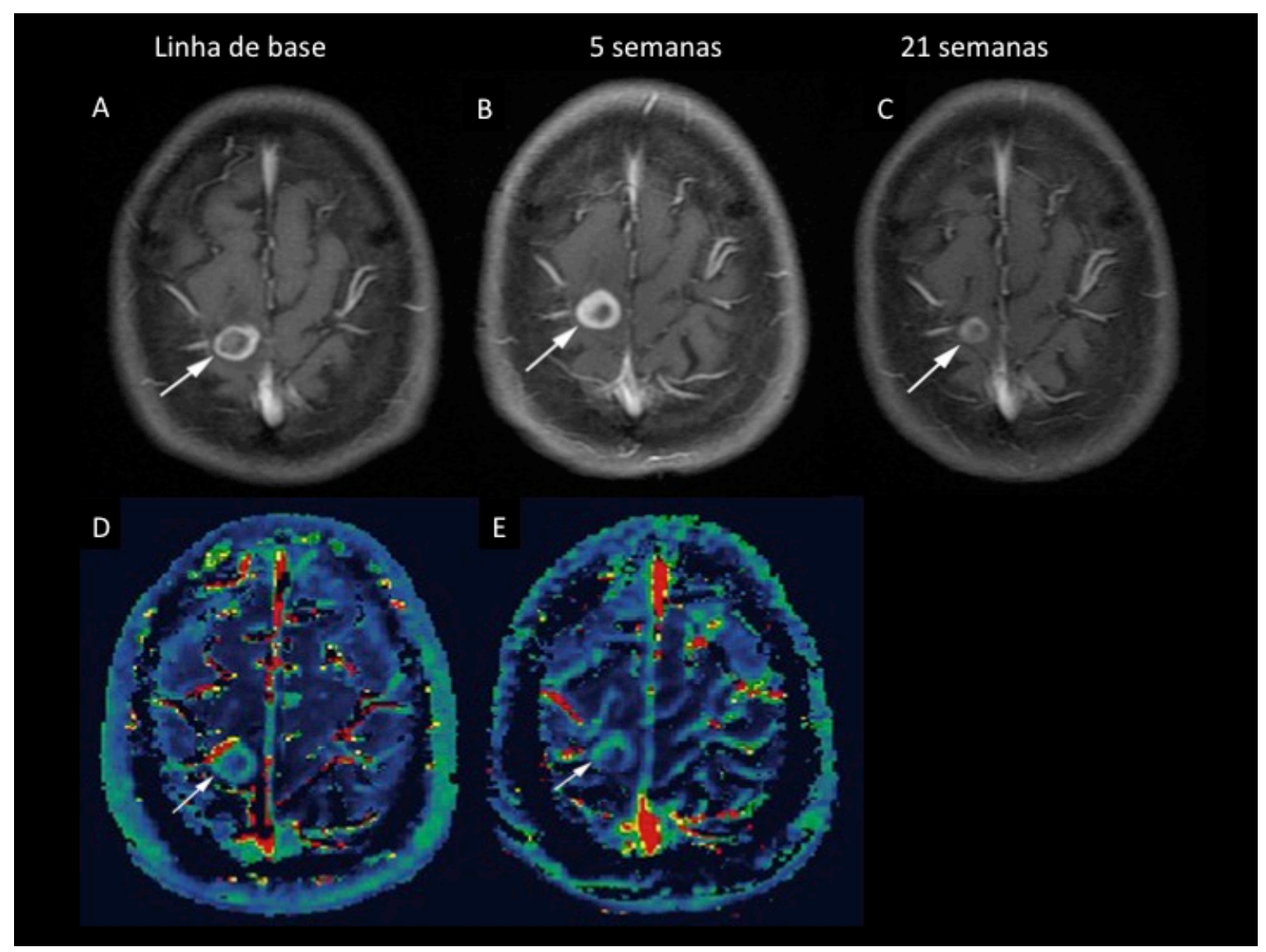

Figura 11. Redução volumétrica tumoral (caso 6). Imagens de RM obtidas em paciente do sexo masculino, 55 anos, com metástase pulmonar frontal direita (setas). A, B, e C: imagens axiais ponderadas em T1 pós-contraste; D e E: mapas paramétricos de Ktrans. Após 5 semanas de acompanhamento, o tumor apresentou um aumento de volume de $12 \%$, enquanto o valor Ktrans reduziu $56 \%$ em comparação aos valores basais. Após 21 semanas de acompanhamento, o volume do tumor apresentou uma diminuição de $78 \%$ rem relação ao valor basal 


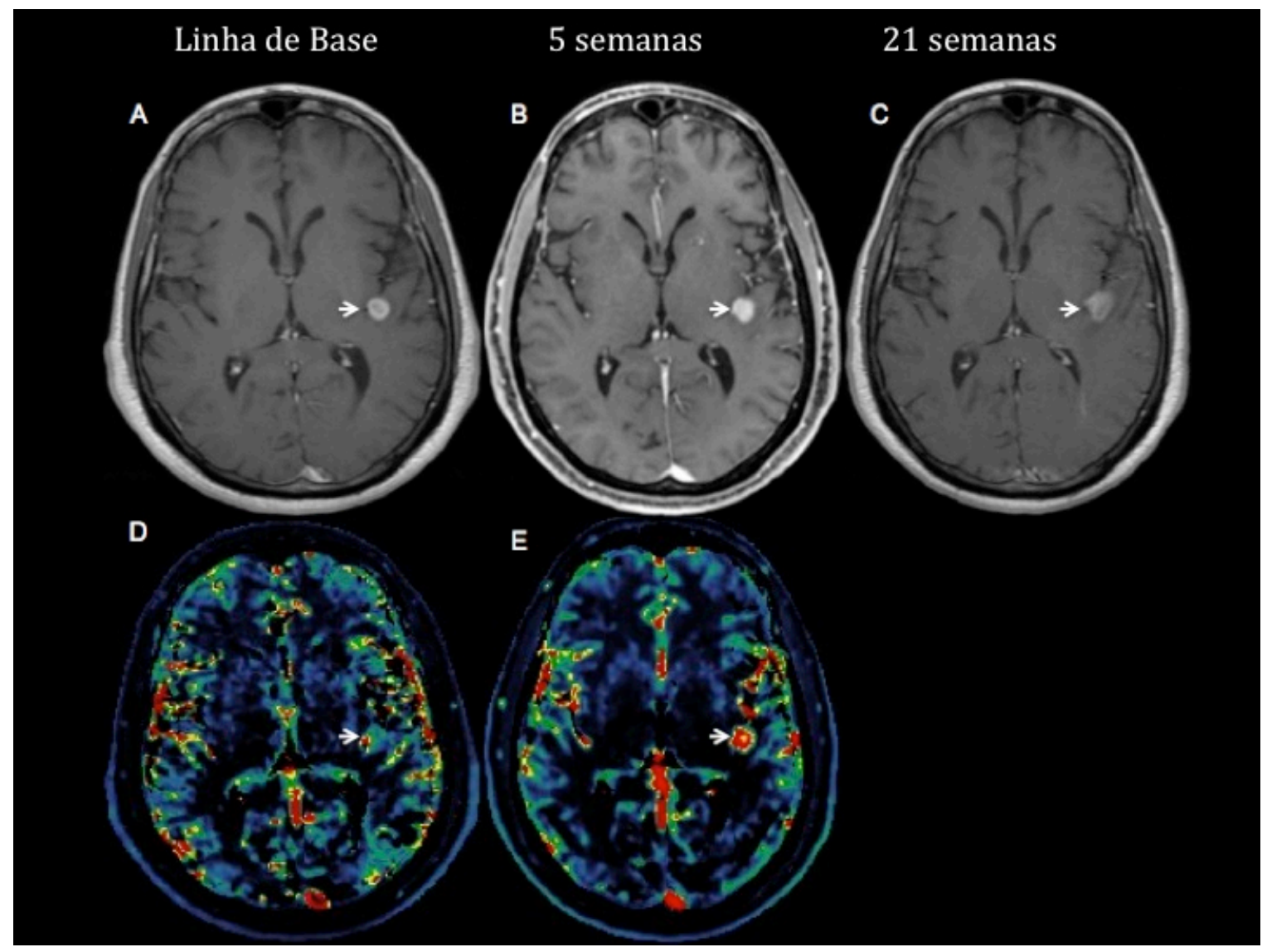

Figura 12. Progressão volumétrica tumoral (caso 11). Imagens de RM obtidas em paciente do sexo masculino, 49 anos, com metástase de melanoma temporal esquerda (setas). A, B, e C: imagens axiais ponderadas em T1 pós-contraste; D e E: mapas paramétricos de Ktrans. Após 5 semanas de acompanhamento, em comparação aos valores basais, a lesão apresentou um aumento de volume de $57 \%$ e um aumento de Ktrans de cerca de 305\%. Após 21 semanas de acompanhamento, o volume do tumor aumentou $75 \%$ em relação à linha de base 


\section{DISCUSSÃO}

Este estudo longitudinal avaliou o efeito da radiocirurgia sobre a permeabilidade das lesões mestastáticas encefálicas. A permeabilidade da lesão foi avaliada por meio do parâmetro Ktrans, obtido através de sequência dinâmica de RM ponderada em T1, após a injeção de contraste paramagnético. Este foi o primeiro estudo longitudinal na literatura consultada a avaliar o papel desta técnica especificamente para metástases encefálicas.

\subsection{ESTUDO DA PERMEABILIDADE DA BARREIRA HEMATOENCEFÁLICA POR RESSONÂNCIA MAGNÉTICA}

A técnica de permeabilidade por RM é comprovadamente útil para a caracterização da microvasculatura (9-11,30). Atualmente, os parâmetros disponíveis usados para descrever a permeabilidade do tecido, com base em modelos compartimentados, incluem Ktrans (coeficiente de transferência), kep (constante de velocidade) e ve (volume intersticial) (10, 11, 31). A vantagem da utilização do Ktrans como um parâmetro é a possibilidade de medir quantitativamente a extensão da acumulação de contraste como uma função do tempo $(10,11)$. O Ktrans reflete permeabilidade capilar se o movimento intercompartimental do traçador não é restringido pelo fluxo sanguíneo regional 
(11). Especificamente para tumores encefálicos, o Ktrans constitui uma boa medida para avaliação da integridade da barreira hematoencefálica $(11,23)$. No entanto, a comparação dos valores de Ktrans da literatura é complicada pela utilização de diferentes parâmetros de aquisição de imagem e diferentes modelos de pós-processamento $(11,30)$. Esta variação do parâmetro dificulta a definição de valores de referência normativos para Ktrans. O desenho longitudinal do nosso estudo permitiu a avaliação das alterações nas medidas do Ktrans que ocorreram em cada tumor individualmente, como resultado do tratamento com radiocirurgia.

Outras técnicas de RM também foram estudadas na literatura para medir a integridade da barreira hematoencefálica, tais como sequência dinâmica de susceptibilidade (DSC) e arterial spin labling (ASL). Em DSC, a análise de dados é limitada porque baseia-se na conversão de sinal em concentrações do agente de contraste (11). Usando este método, os valores de Ktrans podem ser imprecisos em lesões com barreira hematoencefálica muito permeável, inclusive metástases (23). Outra desvantagem de DSC é a capacidade de medir apenas a permeabilidade na primeira passagem de contraste. Em relação ao ASL, um estudo anterior concluiu que não há precisão suficiente na medição da permeabilidade capilar usando a técnica de aquisição atualmente disponível (32). 


\subsection{PERMEABILIDADE DAS LESÕES METASTÁTICAS ENCEFÁLICAS TRATADAS COM RADIOCIRURGIA}

No presente estudo, observou-se uma redução significativa nos valores de Ktrans das metástases encefálicas no período de 4 a 8 semanas após a RC. Resultados semelhantes já haviam sido descritos por Cao et. al., ao estudar radioterapia fracionada no tratamento de astrocitomas malignos (33). Eles observaram uma redução gradual dos valores de Ktrans após seis semanas da conclusão do tratamento, sendo que as alterações foram mais rápidas e significativas quanto maior a dose de radiação utilizada.

Correlacionando-se aos resultados de estudos experimentais, podemos especular que os efeitos da RC sobre os valores Ktrans de tumores encefálicos estão provavelmente relacionados às mudanças na barreira hematoencefálica e com os danos vasculares causados pela radiação (31). Embora numa fase aguda (24 horas após a irradiação), a morte e apoptose de células endoteliais possam aumentar a permeabilidade da barreira hematoencefálica, posteriormente, um padrão de vasculopatia oclusiva tende a se desenvolver, resultando numa diminuição gradual desta permeabilidade (34). Inicialmente, na fase subaguda precoce (semanas a meses), a vasculopatia oclusiva está relacionada ao colapso e oclusão capilar pela agregação plaquetária e formação de trombos. Subsequentemente, na fase tardia (meses a anos), ocorrem a degeneração fibrinóide das paredes vasculares e a proliferação de células 
endoteliais e pericíticas $(23,31,33,34)$.

Os nossos resultados indicaram também que a razão de Ktrans, aferida pela comparação entre as medidas pré e pós (4 - 8 semanas) radiocirurgia, foi um preditor significativo do desfecho do volume tumoral local a médio prazo. Cada unidade de aumento na razão de Ktrans foi associado com um aumento de $50 \%$ no risco de progressão volumétrica tumoral a médio prazo. Demonstramos ainda que um aumento $\geq 15 \%$ no valor de Ktrans das metástases encefálicas no período de 4 a 8 semanas após a radiocirurgia previu o fracasso do tratamento em reduzir as dimensoes tumorais com uma sensibilidade de $78 \%$ e uma especificidade de $85 \%$. Estes resultados são importantes para a determinação mais precoce de terapias alternativas aos não possíveis respondedores. Peng et al. utilizando técnica de RM semelhante também demonstraram que as medições do Ktrans constituem valiosa ferramenta na distinção entre respondedores e não respondedores à radioterapia (31). No entanto, uma comparação direta entre o referido estudo e o nosso é limitada porque a amostra deles incluiu apenas dois casos de metástases encefálicas tratados com radioterapia de cerébro total, ao invés de radiocirurgia.

Exames sequenciais de RM representam o método convencional para o monitoramento da resposta tumoral ao tratamento radiocirúrgico $(2-4,8)$. No entanto, um longo período de acompanhamento é necessário para que as medições de tamanho do tumor possam ser suficientemente precisas para a determinação do resultado do tratamento $(3,4,8,35)$. Técnicas avançadas de RM podem potencialmente fornecer informações adicionais mais precocemente. Estudos recentes sugerem que a difusão e a perfusão foram capazes de detectar a resposta de tumores encefálicas ao tratamento mais precoce do que a 
RM convencional $(8,20,21,35)$. O nosso achado de que um aumento precoce no valor de Ktrans foi associado com um aumento do risco para a progressão volumétrica do tumor no seguimento a médio prazo sugere que o DCE MRI pode também ser uma ferramenta valiosa para a avaliação inicial da resposta ao tratamento. É possível que a combinação das três técnicas avançadas de RM possa mostrar melhor desempenho.

Os nossos resultados indicaram também que as metástases encefálicas com maiores valores de Ktrans antes do tratamento radioterápico apresentaram menor taxa de crescimento tumoral. Por um lado, este foi um resultado surpreendente, considerando-se que maior valor de Ktrans foi correlacionado em estudo pregresso a maior grau tumoral e, consequentemente, a maior número de mitoses (12). Por outro lado, a maior permeabilidade da barreira hematoencefálica pode conferir à lesão tumoral uma maior sensibilidade aos tratamentos radioterápico e quimioterápico (36). Estudos preliminares avaliando especificamente tumores encefálicos não estão disponíveis, porém Baba $\mathrm{Y}$ et al.(32) demonstraram que o índice de permeabilidade (Ktrans) foi o único preditor significativo pré-tratamento para resposta tumoral à radioterapia em neoplasias malignas de cabeça e pescoço. É possível que o valor basal de Ktrans possa refletir a concentração de oxigênio do tumor, predispondo-o ou não à hipóxia induzida pela radioterapia, assim como a capacidade de drogas antineoplásicas atravessarem a barreira hematoencefálica (36). 


\subsection{LIMITAÇÕES}

O tamanho da amostra relativamente pequena e o número relativamente elevado de pacientes que perderam o seguimento pode ter limitado algumas análises, como o impacto da RC no volume do tumor a médio prazo. Além disso, o tamanho amostral não permitiu avaliação de possíveis fatores de confundimento, como tratamento quimioterápicos e com outras drogas.

O período de seguimento deveria ser idealmente maior e a avaliação histológica após a terapia seria um parâmetro mais adequado para classificação da resposta tumoral. No entanto, considerando o estado clínico crítico e o prognóstico da maioria dos pacientes com metástases encefálicas, intervenções invasivas devem ser evitadas e não são justificáveis.

Em relação à mensuração do valor de Ktrans e do volume tumoral, o fato de apenas um radiologista ter realizado as medidas pode ter acarretado algum viés de aferição. Além disso, a fórmula utilizada para obtenção de volume pode incorrer em erros caso as lesões apresentem formas bizarras. Entretanto, praticamente todas as metástases do estudo apresentavam forma elipsóide. Destaca-se ainda que a inclusão de tecido necrótico pode ter reduzido o verdadeiro valor de Ktrans das lesões. Isso, no entanto, não limitou as inferências propostas pelo estudo.

A existência de lesões metastáticas de diferentes histologias e, portanto, 
com diferentes permeabilidades e respostas ao tratamento, pode ter atenuado as diferenças encontradas entre os valores de Ktrans. Por outro lado, o desenho longitudinal do estudo permitiu a avaliação das alterações de Ktrans num mesmo indivíduo em função do tratamento.

Este estudo limitou-se a avaliação quantitativa relativa dos valores de Ktrans. A utilização de parâmetros pré-fixados no processamento das imagens, como função de entrada arterial e intensidade de sinal em T1, ao mesmo tempo que conferiu homogeneidade para as comparações pré e pós-tratamento, não permitiu pontos de corte absolutos para valores de Ktrans.

O volume tumoral a médio prazo (> 16 semanas) foi o critério utilizado para classificar os resultados da radiocirurgia sobre a lesão metastática. Entretanto, a mudança no tamanho do tumor não é um processo linear, e as metástases têm taxas variáveis de regressão e crescimento (3). No entanto, estudos anteriores usando critérios semelhantes demonstraram que as boas respostas iniciais, avaliadas através de redução do volume tumoral, geralmente se traduzem em controle local persistente em posteriores exames de imagem (6).

\subsection{FUTURAS DIREÇÕES}

Avaliar a resposta das metástases encefálicas à radiocirurgia no período 
pós-tratamento precoce é um grande desafio que os radiologistas, neurocirurgiões, radioterapeutas e oncologistas enfrentam rotineiramente. Este estudo demonstrou que a avaliação de Ktrans usando a técnica de permeabilidade por RM no período pós-tratamento precoce após radiocirurgia foi capaz de prever o resultado do volume tumoral a médio prazo. Este resultado pode impactar na qualidade de vida e sobrevida dos pacientes com metástases encefálicas ao contribuir, com mais um parâmetro, para determinação precoce da resposta ou falência ao tratamento, ajudando na escolha de terapias alternativas em pacientes que não responderam.

Entretanto, são necessários outros estudos, em diferentes centros, para que os resultados aqui apresentados sejam confirmados e reproduzidos. A alteração do Ktrans após radiocirurgia deverá ser interpretada em conjunto com outros parâmetros clínicos e de imagem para identificar com maior segurança os pacientes que apresentaram um bom ou mau desfecho à radiocirurgia.

Este estudo também contribuiu para o avanço do conhecimento sobre a técnica de permeabilidade por RM, ainda não amplamente empregada na prática diária do radiologista. $\mathrm{O}$ entendimento do comportamento da barreira hematoencefálica nestas lesões pode proporcionar novas alternativas terapêuticas, incluindo quimioterápicos ou mesmo drogas anti-angiogênicas. 


\section{CONCLUSÕES}

1. A RC está associada a redução do parâmetro Ktrans no período póstratamento precoce (4 a 8 semanas).

2. A variação dos valores de Ktrans entre a linha de base e o período póstratamento precoce (4 a 8 semanas) pode prever o volume tumoral a médio prazo (> 16 semanas) depois da RC. 


\section{REFERÊNCIAS}

1. Ranjan T, Abrey LE. Current management of metastatic brain disease. Neurotherapeutics. 2009;6(3):598-603.

2. Suh JH. Stereotactic radiosurgery for the management of brain metastases. N Engl J Med.362(12):1119-27.

3. Rahman M, Cox JB, Chi YY, Carter JH, Friedman WA. Radiographic response of brain metastasis after linear accelerator radiosurgery. Stereotactic and functional neurosurgery. 2012;90(2):69-78.

4. Kang TW, Kim ST, Byun HS, Jeon P, Kim K, Kim H, et al. Morphological and functional MRI, MRS, perfusion and diffusion changes after radiosurgery of brain metastasis. European journal of radiology. 2009;72(3):370-80.

5. Huber PE, Hawighorst H, Fuss M, van Kaick G, Wannenmacher MF, Debus J. Transient enlargement of contrast uptake on MRI after linear accelerator (linac) stereotactic radiosurgery for brain metastases. Int $\mathrm{J}$ Radiat Oncol Biol Phys. 2001;49(5):1339-49.

6. Peterson AM, Meltzer CC, Evanson EJ, Flickinger JC, Kondziolka D. MR imaging response of brain metastases after gamma knife stereotactic radiosurgery. Radiology. 1999;211(3):807-14.

7. Ross DA, Sandler HM, Balter JM, Hayman JA, Archer PG, Auer DL. Imaging changes after stereotactic radiosurgery of primary and secondary malignant brain tumors. J Neurooncol. 2002;56(2):175-81.

8. Shah R, Vattoth S, Jacob R, Manzil FF, O'Malley JP, Borghei P, et al. Radiation necrosis in the brain: imaging features and differentiation from tumor recurrence. Radiographics : a review publication of the Radiological Society of North America, Inc. 2012;32(5):1343-59.

9. Zaharchuk G. Theoretical basis of hemodynamic MR imaging techniques to measure cerebral blood volume, cerebral blood flow, and permeability. AJNR Am J Neuroradiol. 2007;28(10):1850-8. 
10. Provenzale JM, Mukundan S, Dewhirst M. The role of blood-brain barrier permeability in brain tumor imaging and therapeutics. AJR American journal of roentgenology. 2005;185(3):763-7.

11. Kassner A, Thornhill R. Measuring the integrity of the human blood-brain barrier using magnetic resonance imaging. Methods Mol Biol. 2011;686:229-45.

12. Zhang N, Zhang L, Qiu B, Meng L, Wang X, Hou BL. Correlation of volume transfer coefficient Ktrans with histopathologic grades of gliomas. Journal of magnetic resonance imaging : JMRI. 2012;36(2):355-63.

13. Smedby KE, Brandt L, Backlund ML, Blomqvist P. Brain metastases admissions in Sweden between 1987 and 2006. Br J Cancer. 2009;101(11):1919-24.

14. Leite CC, Pincerato RC, Martins MCB, Amaral RPG, Shibao S, Lucato LT. Tumores Intra-axiais. In: Cerri GG, editor. Neurorradiologia: Diagnóstico por Imagem das Alterações Encefálicas. 1a ed. Rio de Janiero: Guanabara Koogan; 2008. p. 288-323.

15. Schomas DA, Roeske JC, MacDonald RL, Sweeney PJ, Mehta N, Mundt AJ. Predictors of tumor control in patients treated with linac-based stereotactic radiosurgery for metastatic disease to the brain. Am J Clin Oncol. 2005;28(2):180-7.

16. Weltman E, Salvajoli JV, Brandt RA, de Morais Hanriot R, Prisco FE, Cruz JC, et al. Radiosurgery for brain metastases: a score index for predicting prognosis. Int J Radiat Oncol Biol Phys. 2000;46(5):1155-61.

17. Park YH, Kim TH, Jung SY, Kim YE, Bae JM, Kim YJ, et al. Combined primary tumor and extracranial metastasis status as constituent factor of prognostic indices for predicting the overall survival in patients with brain metastases. Journal of Korean medical science. 2013;28(2):205-12.

18. Steiner L, Lindquist C, Adler JR, Torner JC, Alves W, Steiner M. Outcome of radiosurgery for cerebral AVM. J Neurosurg. 1992;77(5):823.

19. Uematsu Y, Fujita K, Tanaka Y, Shimizu M, Oobayashi S, Itakura T, et al. Gamma knife radiosurgery for neuroepithelial tumors: radiological and histological changes. Neuropathology. 2001;21(4):298-306. 
20. Essig M, Waschkies M, Wenz F, Debus J, Hentrich HR, Knopp MV. Assessment of brain metastases with dynamic susceptibility-weighted contrast-enhanced MR imaging: initial results. Radiology. 2003;228(1):193-9.

21. Huang CF, Chou HH, Tu HT, Yang MS, Lee JK, Lin LY. Diffusion magnetic resonance imaging as an evaluation of the response of brain metastases treated by stereotactic radiosurgery. Surg Neurol. 2008;69(1):62-8; discussion 8.

22. Chenevert TL, McKeever PE, Ross BD. Monitoring early response of experimental brain tumors to therapy using diffusion magnetic resonance imaging. Clin Cancer Res. 1997;3(9):1457-66.

23. Lacerda S, Law M. Magnetic resonance perfusion and permeability imaging in brain tumors. Neuroimaging Clin N Am. 2009;19(4):527-57.

24. Hoefnagels FW, Lagerwaard FJ, Sanchez E, Haasbeek CJ, Knol DL, Slotman BJ, et al. Radiological progression of cerebral metastases after radiosurgery: assessment of perfusion MRI for differentiating between necrosis and recurrence. J Neurol. 2009;256(6):878-87.

25. Petersen ET, Zimine I, Ho YC, Golay X. Non-invasive measurement of perfusion: a critical review of arterial spin labelling techniques. $\mathrm{Br} \mathrm{J}$ Radiol. 2006;79(944):688-701.

26. Weber MA, Thilmann C, Lichy MP, Gunther M, Delorme S, Zuna I, et al. Assessment of irradiated brain metastases by means of arterial spinlabeling and dynamic susceptibility-weighted contrast-enhanced perfusion MRI: initial results. Invest Radiol. 2004;39(5):277-87.

27. Huang J, Wang AM, Shetty A, Maitz AH, Yan D, Doyle D, et al. Differentiation between intra-axial metastatic tumor progression and radiation injury following fractionated radiation therapy or stereotactic radiosurgery using MR spectroscopy, perfusion MR imaging or volume progression modeling. Magnetic resonance imaging. 2011;29(7):993-1001.

28. Tofts PS. Modeling tracer kinetics in dynamic Gd-DTPA MR imaging. Journal of magnetic resonance imaging : JMRI. 1997;7(1):91-101. 
29. Tofts PS, Kermode AG. Measurement of the blood-brain barrier permeability and leakage space using dynamic MR imaging. 1. Fundamental concepts. Magn Reson Med. 1991;17(2):357-67.

30. Thompson G, Mills SJ, Stivaros SM, Jackson A. Imaging of brain tumors: perfusion/permeability. Neuroimaging Clin N Am. 2010;20(3):337-53.

31. Peng SL, Chen CF, Liu HL, Lui CC, Huang YJ, Lee TH, et al. Analysis of parametric histogram from dynamic contrast-enhanced MRI: application in evaluating brain tumor response to radiotherapy. NMR in biomedicine. 2012.

32. Baba Y, Yamashita Y, Onomichi M, Murakami R, Takahashi M. Dynamic magnetic resonance imaging of head and neck lesions. Top Magn Reson Imaging. 1999;10(2):125-9.

33. Cao Y, Tsien Cl, Sundgren PC, Nagesh V, Normolle D, Buchtel H, et al. Dynamic contrast-enhanced magnetic resonance imaging as a biomarker for prediction of radiation-induced neurocognitive dysfunction. Clin Cancer Res. 2009;15(5):1747-54.

34. Shinoda J, Yano H, Ando H, Ohe N, Sakai N, Saio M, et al. Radiological response and histological changes in malignant astrocytic tumors after stereotactic radiosurgery. Brain Tumor Pathol. 2002;19(2):83-92.

35. Gao X, Zhang XN, Zhang YT, Yu CS, Xu DS. Magnetic resonance imaging in assessment of treatment response of gamma knife for brain tumors. Chinese medical journal. 2011;124(12):1906-10.

36. Baba $Y$, Yamashita $Y$, Onomichi M. Dynamic MR imaging and radiotherapy. Magn Reson Med Sci. 2002;1(1):32-7. 
ANEXOS 


\section{ANEXO A - APROVAÇÃO PELO COMITÊ DE ÉTICA EM PESQUISA}

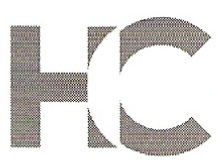

\section{APROVAÇÃO}

A Comissão de Ética para Análise de Projetos de Pesquisa CAPPesq da Diretoria Clínica do Hospital das Clínicas e da Faculdade de Medicina da Universidade de São Paulo, em sessão de 08/09/2010, APROVOU O Protocolo de Pesquisa $n^{\circ}$ 0520/10, intitulado: "AVALIAÇÃO DAS METÁstASES CEREBRAIS ANTES E APÓS RADIOCIRURGIA ATRAVÉS DE TÉCNICAS AVANÇADAS DE RESSONÂNCIA MAGNÉTICA: DIFUSĀO, PERFUSĀO E PERMEABILIDADE." apresentado pelo Departamento de RADIOLOGIA E RADIOTERAPIA, inclusive o Termo de Consentimento Livre e Esclarecido.

Cabe ao pesquisador elaborar e apresentar à CAPPesq, os relatórios parciais e final sobre a pesquisa (Resolução do Conselho Nacional de Saúde n 196, de 10/10/1996, inciso IX.2, letra "c").

Pesquisador (a) Responsável: Cláudia de Cosła Leite

Pesquisador (a) Executante: Daniela Batista de Almeida Freitas

CAPPesq, 09 de Setembro de 2010

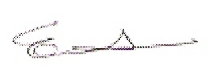

Prof. Dr. Eduardo Massad Presidente da Comissão de Ética para Análise de Projetos de Pesquisa 


\title{
ANEXO B - TERMO DE CONSENTIMENTO LIVRE E ESCLARECIDO
}

\author{
HOSPITAL DAS CLÍNICAS
}

DA

FACULDADE DE MEDICINA DA UNIVERSIDADE DE SÃO PAULO

TERMO DE CONSENTIMENTO LIVRE E ESCLARECIDO

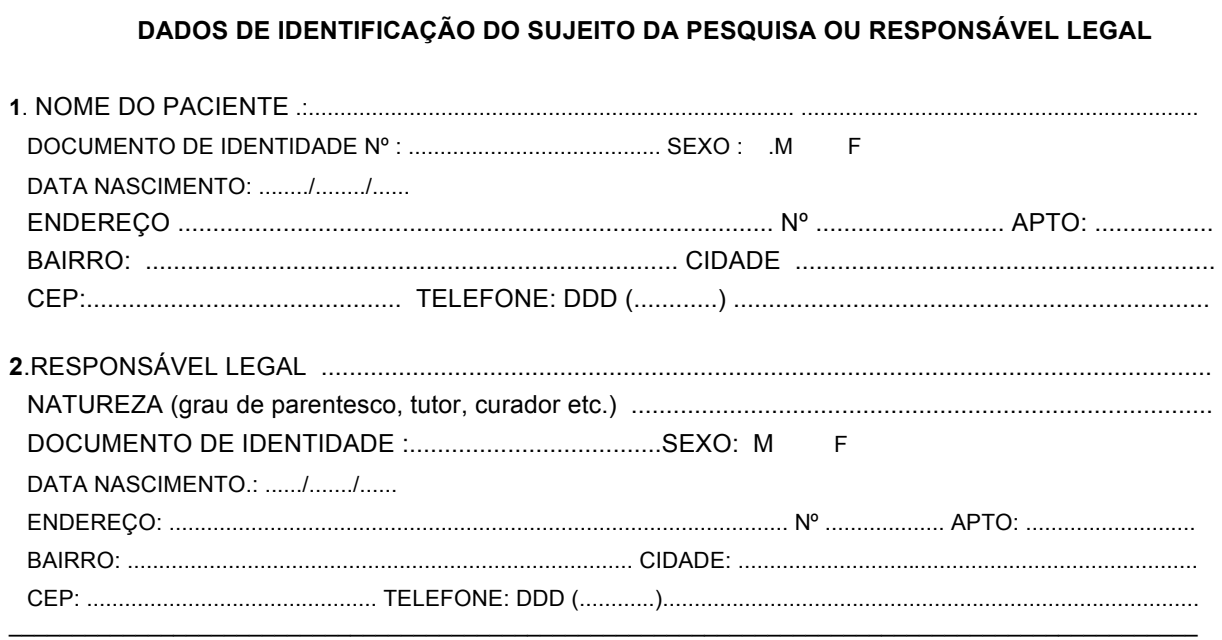

DADOS SOBRE A PESQUISA CIENTÍFICA

1. TÍTULO DO PROTOCOLO DE PESQUISA :

"Avaliação das metástases cerebrais antes e após radiocirurgia através de técnicas avançadas de Ressonância Magnética: Difusão, Perfusão e Permeabilidade”.

PESQUISADOR: Cláudia da Costa leite CARGO/FUNÇÃO: Professora INSCRIÇÃO CONSELHO REGIONAL : 65349 UNIDADE DO HCFMUSP: Instituto de Radiologia

3. AVALIAÇÃO DO RISCO DA PESQUISA: SEM RISCO RISCO MÍNIMO $\mathrm{X}$ RISCO MÉDIO RISCO BAIXO RISCO MAIOR 
Você esta sendo convidado a participar de uma pesquisa cujo objetivo principal é avaliar as imagens do exame de ressonância magnética obtidas de pacientes com metástases cerebrais, antes e após o tratamento com radioterapia, utilizando técnicas modernas na obtenção destas imagens, conhecidas como difusão, permeabilidade e perfusão. O seguimento das metástase cerebrais após a radiocirurgia geralmente é feito por exames de imagem de ressonância magnetica convencional. Entretanto, a resposta avaliada por esta técnica pode demorar muito tempo e as vezes não é tão precisa. Desta forma, são necessárias novas e modernas técnicas de ressonância magnética que possam detectar precocemente ou mesmo predizer o sucesso ou fracasso do tratamento radioterápico.

Todos pacientes serão submetidos à ressonância nuclear magnética do crânio com contraste. Este exame já faz parte do acompanhamento habitual. Serão apenas adicionadas outras sequências ao protocolo de rotina.

Poderá haver pequeno desconforto transitório devido a um discreto aumento (cerca de 5 a 10 minutos) no tempo que o paciente permanecerá na sala de exame.

O participante da pesquisa poderá se beneficiar no planejamento do seu tratamento, já que as novas técnicas de ressonância magnética podem oferecer informações adicionais a cerca da resposta do tumor aos tratamentos já realizados.

A principal investigadora é a Dra Daniela Batista de Almeida Freitas, que pode ser encontrada no endereço Av. Dr. Enéas de Carvalho Aguiar, 255 - 3o.andar - Cerqueira Cesar - São Paulo - SP - CEP: 05403-001, Telefone: (11) 3069-7064. Se você tiver alguma consideração ou dúvida sobre a ética da pesquisa, entre em contato com o Comitê de Ética em Pesquisa (CEP) - Rua Ovídio Pires de Campos, $225-5^{\circ}$ andar - tel: 3069-6442 ramais 16, 17, 18 ou 20, FAX: 3069-6442 ramal 26 - E-mail: cappesq@hcnet.usp.br ou através do telefone (11) 83715605 para esclarecimentos / orientação.

Afirmamos aqui que você terá acesso, a qualquer tempo, às informações sobre riscos e benefícios da pesquisa. Estaremos esclarecendo, a qualquer tempo, dúvidas sobre os procedimentos. Os dados são confidenciais e estarão sobre sigilo e privacidade. Você terá o direito de retirar o seu consentimento a qualquer momento e deixar de participar do estudo, sem que isto traga prejuízo à continuidade da assistência. Não há despesas pessoais para o participante em qualquer fase do estudo, incluindo os exames. Também não há compensação financeira relacionada à sua participação.

Acredito ter sido suficientemente informado a respeito das informações que li ou que foram lidas para mim, descrevendo o estudo " Avaliação das metástases cerebrais antes e após radiocirurgia através de técnicas avançadas de Ressonância Magnética: Difusão, Perfusão e Permeabilidade."

Eu discuti com a Dra. Daniela Batista de Almeida Freitas sobre a minha decisão em participar nesse estudo. Ficaram claros para mim quais são os propósitos do estudo, os procedimentos a serem realizados, seus desconfortos e riscos, as garantias de confidencialidade e de esclarecimentos permanentes. Ficou claro também que minha participação é isenta de despesas e que tenho garantia do acesso a tratamento hospitalar quando necessário. Concordo voluntariamente em participar deste estudo e poderei retirar o meu consentimento a qualquer momento, antes ou durante o mesmo, sem penalidades ou prejuízo ou perda de qualquer benefício que eu possa ter adquirido, ou no meu atendimento neste Serviço.

São Paulo, 
ANEXO C - BASE DE DADOS DEMOGRÁFICOS E CLÍNICOS

\begin{tabular}{crlll}
\hline Caso & Idade & Gênero & $\begin{array}{c}\text { Sítio } \\
\text { primário }\end{array}$ & \multicolumn{1}{c}{ Histologia } \\
\hline 1 & 67 & Mas & pulmão & Carcinoma epidermoide \\
2 & 71 & Fem & mama & Carcinoma ductal infiltrativo \\
3 & 60 & Mas & pulmão & Carcinoma anaplásico \\
4 & 49 & Fem & pele & Melanoma \\
5 & 71 & Mas & pulmão & Adenocarcinoma \\
6 & 55 & Mas & pulmão & Carcinoma epidermóide \\
7 & 31 & Mas & testiculo & Carcinoma embrionário \\
8 & 51 & Fem & mama & Carcinoma ductal infiltrante \\
9 & 49 & Fem & pele & Melanoma \\
10 & 57 & Fem & pulmão & Adenocarcinoma \\
11 & 49 & Mas & pele & Melanoma \\
12 & 67 & Fem & pulmão & Carcinoma epidermoide \\
13 & 32 & Fem & mama & Carcinoma ductal infiltrante \\
14 & 66 & Mas & pulmão & Adenocarcinoma \\
15 & 56 & Mas & pulmão & Adenocarcinoma \\
16 & 44 & Mas & rim & Carcinoma células claras \\
17 & 58 & Fem & pulmão & Adenocarcinoma \\
18 & 72 & Mas & pele & Melanoma \\
19 & 24 & Mas & testiculo & Tumor seio endodérmico \\
20 & 44 & Fem & pulmão & Adenocarcinoma \\
21 & 53 & Mas & pulmão & Adenocarcinoma \\
22 & 65 & Mas & pulmão & Adenocarcinoma \\
23 & 66 & Fem & mama & Carcinoma ductal infiltrante \\
24 & 73 & Fem & rim & Carcinoma células renais \\
25 & 53 & Mas & pulmão & Adenocarcinoma \\
26 & 62 & Fem & pulmão & Adenocarcinoma \\
& & & & \\
\hline & & & & \\
\hline
\end{tabular}


ANEXO C - BASE DE DADOS APÓS ANÁLISE DAS IMAGENS

\begin{tabular}{|c|c|c|c|c|c|c|c|}
\hline Caso & Local da lesão & $\begin{array}{l}\text { Dose } \\
\text { RC }\end{array}$ & $\begin{array}{c}\text { Ktrans } \\
\text { base }\end{array}$ & $\begin{array}{c}\text { Volume } \\
\text { base }\end{array}$ & $\begin{array}{l}\text { Ktrans } \\
\text { precoce }\end{array}$ & $\begin{array}{l}\text { Volume } \\
\text { precoce }\end{array}$ & $\begin{array}{c}\text { Volume } \\
\text { tardio }\end{array}$ \\
\hline 1 & Cerebelar & 18 & 0.142 & 2.630 & 0.064 & 0.5 & ND \\
\hline 1 & Temporal direita & 18 & 0.142 & 1.019 & 0.055 & 0.230 & ND \\
\hline 2 & Occipital direita & 20 & 0.210 & 0.330 & 0.0179 & 0.170 & 0.170 \\
\hline 3 & $\begin{array}{l}\text { Parietal direita } \\
\text { Frontoparietal }\end{array}$ & 20 & 0.035 & 1.409 & 0.054 & 0.959 & 3.299 \\
\hline 4 & esquerda & 20 & 0.100 & 0.07 & 0.100 & 0.059 & 0.07 \\
\hline 4 & $\begin{array}{l}\text { Parietal direita } \\
\text { Occiptal }\end{array}$ & 20 & 0.209 & 0.469 & 0.129 & 0.059 & 0.039 \\
\hline 5 & esquerda & 20 & 0.017 & 0.620 & 0.001 & 0.54 & ND \\
\hline 6 & Frontal direita & 18 & 0.239 & 2.200 & 0.104 & 2.5 & 0.479 \\
\hline 7 & Occiptal direita & 25 & 0.358 & 0.289 & 0.057 & 0.09 & 0.029 \\
\hline 8 & Frontal direita & 18 & 0.263 & 0.460 & 0.223 & 0.2 & 0.07 \\
\hline 9 & $\begin{array}{l}\text { Occipital direita } \\
\text { Cerebelar }\end{array}$ & 20 & 0.177 & 1.370 & 0.116 & 3.140 & 5.980 \\
\hline 10 & $\begin{array}{l}\text { esquerda } \\
\text { Temporal }\end{array}$ & 12 & 0.270 & 2.519 & 0.231 & 0.33 & ND \\
\hline 10 & $\begin{array}{l}\text { Direita } \\
\text { Parietal }\end{array}$ & 20 & 0.340 & 0.300 & 0.275 & 0.039 & ND \\
\hline 11 & $\begin{array}{l}\text { esquerda } \\
\text { Temporal }\end{array}$ & 20 & 0.014 & 2.700 & 0.164 & 1.700 & 26 \\
\hline 11 & $\begin{array}{l}\text { esquerda } \\
\text { Temporal }\end{array}$ & 20 & 0.017 & 0.569 & 0.068 & 0.899 & 1 \\
\hline 12 & $\begin{array}{l}\text { esquerda } \\
\text { Frontal }\end{array}$ & 20 & 0.094 & 0.330 & 0.078 & 0.079 & ND \\
\hline 13 & esquerda & 18 & 0.048 & 0.129 & 0.068 & 3.900 & 18.399 \\
\hline 14 & Frontal direita & 20 & 0.092 & 0.129 & 0.057 & 0.079 & 0.02 \\
\hline 15 & Frontal direita & 16 & 0.134 & 9.399 & 0.141 & 2 & ND \\
\hline 16 & $\begin{array}{l}\text { Frontal direita } \\
\text { Temporal }\end{array}$ & 18 & 0.187 & 3.150 & 0.07 & 15.279 & ND \\
\hline 16 & $\begin{array}{c}\text { esquerda } \\
\text { Frontoparietal }\end{array}$ & 18 & 0.114 & 0.610 & 0.035 & 3.650 & ND \\
\hline 17 & $\begin{array}{l}\text { esquerda } \\
\text { Frontal }\end{array}$ & 18 & 0.008 & 0.127 & 0.017 & 0.039 & 0.01 \\
\hline 18 & $\begin{array}{l}\text { esquerda } \\
\text { Frontal }\end{array}$ & 20 & 0.039 & 0.230 & 0.025 & 0.170 & 0.079 \\
\hline 18 & esquerda & 18 & 0.026 & 0.670 & 0.012 & 0.449 & 0.600 \\
\hline 18 & $\begin{array}{l}\text { Occipital direita } \\
\text { Occiptal }\end{array}$ & 18 & 0.027 & 1.259 & 0.033 & 1.330 & 2.095 \\
\hline 19 & $\begin{array}{l}\text { esquerda } \\
\text { Cerebelar }\end{array}$ & 16 & 0.01 & 8.899 & 0.001 & 1.799 & ND \\
\hline 20 & direita & 16 & 0.398 & 5.5 & 0.122 & 3 & ND \\
\hline 21 & $\begin{array}{l}\text { Frontal direita } \\
\text { Occipital }\end{array}$ & 20 & 0.022 & 0.079 & 0.041 & 0.189 & 0.37 \\
\hline 22 & $\begin{array}{l}\text { esquerda } \\
\text { Cerebelar }\end{array}$ & 20 & 0.027 & 1.100 & 0.011 & 0.5 & ND \\
\hline 23 & $\begin{array}{l}\text { esquerda } \\
\text { Frontal }\end{array}$ & 20 & 0.209 & 1.039 & 0.163 & 1.159 & 1.799 \\
\hline 24 & $\begin{array}{c}\text { esquerda } \\
\text { Parietal }\end{array}$ & 19 & 0.097 & 0.740 & 0.184 & 0.670 & 0.029 \\
\hline 24 & $\begin{array}{c}\text { esquerda } \\
\text { Mesencefalica }\end{array}$ & 20 & 0.150 & 0.0904 & 0.093 & 0.051 & 0.01 \\
\hline 25 & $\begin{array}{l}\text { esquerda } \\
\text { Cerebelar }\end{array}$ & 16 & 0.115 & 0.639 & 0.021 & 0.07 & 0.02 \\
\hline 26 & esquerda & 18 & 0.02 & 1.059 & 0.023 & 1.5 & 1.5 \\
\hline
\end{tabular}


ANEXO D - PUBLICAÇÃO DE ARTIGO EM PERIÓDICO

Assessment of irradiated brain metastases using dynamic contrast-enhanced magnetic resonance imaging

\section{Daniela B. Almeida-Freitas, Marco}

C. Pinho, Maria C. G. Otaduy, Henrique F. Braga, Daniel Meira-Freitas \& Claudia da Costa Leite

Neuroradiology

A Joumal Devoted to Neuroimaging and Interventional Neuraradiology

ISSN 0028-3940

Neuroradiology

DOl $10.1007 / 500234-014-1344-0$

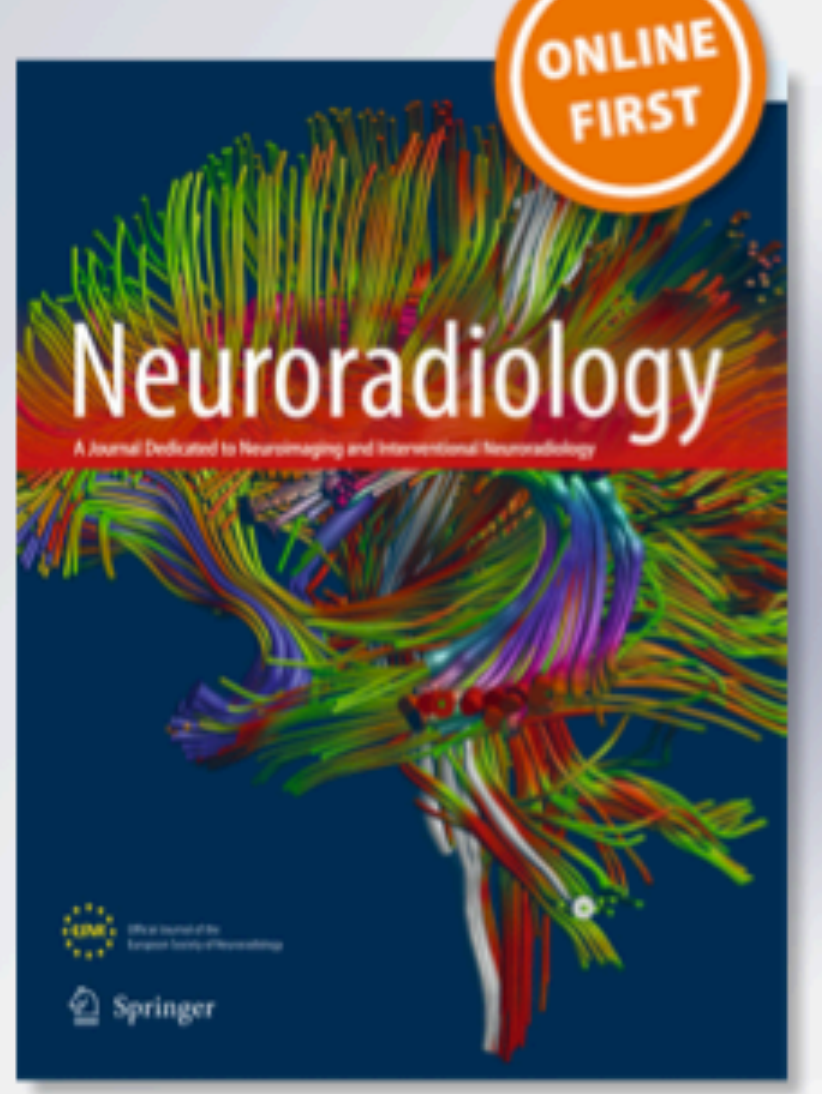

\section{Springer}




\section{Assessment of irradiated brain metastases using dynamic contrast-enhanced magnetic resonance imaging}

Daniela B. Almeida-Freitas • Marco C. Pinho •

Maria C. G. Otaduy • Henrique F. Braga •

Daniel Meira-Freitas • Claudia da Costa Leite

Received: 27 October 2013 / Accepted: 14 February 2014 /Published online: 21 March 2014

(C) Springer-Verlag Berlin Heidelberg 2014

\section{Abstract}

Introduction The purpose of this study was to evaluate the effect of stereotactic radiosurgery (SRS) on cerebral metastases using the transfer constant $\left(K_{\text {trans }}\right)$ assessed by dynamic contrast-enhanced (DCE) MRI. Furthermore, we aimed to evaluate the ability of $K_{\text {trans }}$ measurements to predict midterm tumor outcomes after SRS

Methods The study received institutional review board approval, and informed consent was obtained from all subjects. Twenty-six adult patients with a total of 34 cerebral metastases underwent T1-weighted DCE MRI in a 1.5-T magnet at baseline (prior to SRS) and 4-8 weeks after treatment. Quantitative analysis of DCE MRI was performed by generating $K_{\text {trans }}$ parametric maps, and region-of-interest-based measurements were acquired for each metastasis. Conventional MRI was performed at least 16 weeks after SRS to assess midterm tumor outcome using volume variation.

D. B. Almeida-Freitas $\cdot$ M. C. G. Otaduy $\cdot$ C. da Costa Leite Department of Radiology, University of São Paulo, São Paulo, Brazil

D. B. Almeida-Freitas $(\bowtie)$

Department of Radiology, University of California, San Diego, CA,

USA

e-mail: daniela.ba@gmail.com

M. C. Pinho

Department of Radiology, University of Texas Southwestern Medical Center, Dallas, TX, USA

H. F. Braga

Department of Radiotherapy, University of São Paulo, São Paulo, Brazil

D. Meira-Freitas

Federal University of São Paulo, São Paulo, Brazil
Results The mean $( \pm \mathrm{SD}) K_{\text {trans }}$ value was $0.13 \pm 0.11 \mathrm{~min}^{-1}$ at baseline and $0.08 \pm 0.07 \mathrm{~min}^{-1}$ after $4-8$ weeks post-treatment $(p<0.001)$. The mean $( \pm \mathrm{SD})$ total follow-up time was $7.9 \pm$ 4.7 months. Seventeen patients (22 lesions) underwent midterm MRI. Of those, nine (41\%) lesions had progressed at the midterm follow-up. An increase in $K_{\text {trans }}$ after SRS was predictive of tumor progression (hazard ratio $=1.50 ; 95 \% \mathrm{CI}=$ $1.16-1.70, p<0.001)$. An increase of $15 \%$ in $K_{\text {trans }}$ showed a sensitivity of $78 \%$ and a specificity of $85 \%$ for the prediction of progression at midterm follow-up.

Conclusion SRS was associated with a reduction of $K_{\text {trans }}$ values of the cerebral metastases in the early post-treatment period. Furthermore, $K_{\text {trans }}$ variation as assessed using DCE MRI may be helpful to predict midterm outcomes after SRS.

Keywords Brain metastasis · MRI · Stereotactic radiosurgery $\cdot$ Brain tumor

\section{Introduction}

Cerebral metastases are the most common intracranial tumors in adults and occur in approximately $15-25 \%$ of all cancer patients [1]. Stereotactic radiosurgery (SRS) is a non-invasive alternative to surgical resection of brain metastasis, with several studies supporting its effectiveness [1-3]

Radiological criteria to evaluate the response of brain metastases to SRS in the early post-treatment period have not been well established. The most frequently used criterion for this purpose is tumor size, which may increase as a result of tumor progression or early radiation-related changes such as edema and inflammation [3-8]. Indeed, Huber et al. reported a transient tumor volume increase of $12 \%$ in all brain metastases after SRS despite a treatment failure rate of $7 \%$ [6]. Therefore, an imaging method that could be used to detect early tumor response would be helpful in identifying the true 
early response of the tumor after SRS treatment. This accurate evaluation of tumor response would thus be helpful to more efficiently predict midterm SRS treatment outcomes.

Dynamic contrast-enhanced (DCE) MRI provides additional information regarding blood-brain barrier integrity [9, 10] using repeated T1-weighted sequences over the course of several minutes following the bolus injection of a paramagnetic gadolinium-based contrast agent (GBCA) [11]. The quantitative analysis of DCE MRI utilizes a pharmacokinetic model that can estimate the extent of contrast accumulation as a function of time - the transfer constant $\left(K_{\text {trans }}\right)[10,11]$. This parameter is directly proportional to the level of permeability of the blood-brain barrier [9]. A recent study demonstrated that $K_{\text {trans }}$ is frequently higher in high-grade tumors [12]. However, the role of $K_{\text {trans }}$ in the assessment of irradiated brain metastases has not been investigated.

The purpose of this study was to evaluate the effect of SRS on cerebral metastases with $K_{\text {trans }}$ that was assessed using DCE MRI. Furthermore, we aimed to evaluate the ability of $K_{\text {trans }}$ measurements to predict midterm tumor outcomes after SRS.

\section{Methods}

Study design and population

This was a prospective observational longitudinal study that recruited adult patients with radiological evidence of cerebral metastases and clinical indication of SRS from two radiotherapy services that were referred for MRI examination. SRS was clinically indicated according to patient age, performance status, extent of systemic disease, number, size, location, and histology of brain metastases [score index for radiosurgery $(\mathrm{SIR}) \geq 4$ ] [13]. All the patients underwent T1-weighted DCE MRI prior to SRS and again 4 to 8 weeks after treatment. The subjects were subsequently followed using routine institutional protocol, which consisted of both a clinical exam and a conventional MRI every 2 to 3 months. This prospectively designed study received institutional review board approval at all involved sites, and informed consent was obtained from all the participants.

\section{Radiation therapy}

All patients underwent a single high-dose SRS performed using a Clinac 6EX photon linear accelerator (Varian, Palo Alto, CA, USA). Five patients received whole-brain radiation therapy prior to SRS with a mean dose of 3,000 cGy divided into ten fractions. According to the protocol of the institution, no patient received steroid therapy to prevent cerebral edema.
All patients received additional chemotherapy, before or after the radiation treatment.

Imaging protocol

MRI was performed with an eight-channel head coil in a 1.5-T scanner (General Electric Medical Systems, Waukesha, WI, USA). DCE MRI was added to the usual brain tumor institutional protocols using a spoiled gradient acquisition steady state technique with the following parameters: repetition time/ echo time, 5.9/1.9 ms; matrix size, $192 \times 192$; field of view, $256 \mathrm{~mm}$; section thickness, $7 \mathrm{~mm}$; flip angle, 14; and number of excitations, 0.67 . Fifty dynamic phases were obtained with a temporal sampling interval of $5.56 \mathrm{~s}$ and a total imaging time of $6.5 \mathrm{~min}$. The bolus injection of $0.05 \mathrm{mmol} / \mathrm{kg}$ of the contrast agent (Magnevist; Schering, Germany or Dotarem; Guerbet, France) was administered after the fifth set of dynamic images at a rate of $3-4 \mathrm{~mL} / \mathrm{s}$.

Data analysis

DCE MRI data were processed using commercially available software (NordicICE v3.3.12; Nordic Imaging Lab, NIL, Bergen, Norway). This software applies the previously described parametric two-compartment tracer kinetic modeling of the dynamic contrast agent response for estimation of $K_{\text {trans }}$ [14]. The arterial input function was determined with the autodetect software tool after motion correction. The baseline (precontrast) T1 value was fixed at a specified value for all of the voxels.

Parametric maps were used to measure $K_{\text {trans }}$ at the regions of interest (ROIs) and were placed on the tumors using T1 post-contrast images by a neuroradiologist who was blinded to the study time point. The ROI had a minimum size of 50 voxels and included all the enhancing and necrotic tumor tissues. Necrotic tumor tissue was included in order to ensure this minimal resolution because many lesions had a very small size. $K_{\text {trans }}$ measurements were determined for all the transaxial sections of each lesion at two time points in the study [baseline (prior to SRS) and early post-treatment period (4 to 8 weeks)], and the highest (maximum) values were used for analysis. The maximum $K_{\text {trans }}$ values were used to minimize the risk of underestimating the permeability of possible viable tumor areas.

For tumor volume estimation, the same neuroradiologist who was blinded to the study time points measured the greatest tumor diameters in three orthogonal planes (anterior-posterior, $\mathrm{d} 1$; transverse, $\mathrm{d} 2$; and superior-inferior, $\mathrm{d} 3$ ) using a three-dimensional post-contrast T1-weighted spoiled gradient-echo acquisition as usually requested by the radiotherapy service of our institution. The tumor volumes were subsequently calculated for each of the three time points [baseline (prior SRS), early follow-up (4 to 8 weeks), and 
midterm follow-up ( $>16$ weeks)], according to the following ellipsoid formula:

$$
\text { Volume }=\frac{4}{3} \times \pi \times\left(\frac{d 1}{2} \times \frac{d 2}{2} \times \frac{d 3}{2}\right)
$$

The midterm outcome was determined by comparing the tumor volume at the midterm follow-up versus that at baseline: good response (decrease in tumor volume of $>25 \%$ ), stable disease (decrease in tumor volume of $<25 \%$ or an increase in tumor volume of $<25 \%$ ), and tumor progression (increase in tumor volume of $>25 \%$ ) [15].

\section{Statistical analysis}

All statistical analyses were performed with commercially available software (Stata version 12.0; StataCorp LP). The alpha level (type I error) was set at 0.05 . The comparison of $K_{\text {trans }}$ measurements between two time points was performed using a generalized estimation equation with robust standard errors to adjust for a potential correlation between different metastases within the same individual. The tumor volumes did not present a normal distribution, and the results were expressed using the median, first quartile (Q1), and third quartile (Q3). The comparison of tumor volumes between time points was performed using the Wilcoxon test. The relationship between $K_{\text {trans }}$ and tumor volume was assessed using Spearman's rank correlation coefficient with the $K_{\text {trans }}$ ratio and tumor growth ratio as variables. The $K_{\text {trans }}$ ratio was defined as the difference between the early post-treatment $K_{\text {trans }}$ and the baseline $K_{\text {trans }}$ divided by the baseline $K_{\text {trans }}$. The tumor growth ratio was defined as the difference between the midterm ( $>16$ weeks) post-treatment tumor volume and the baseline tumor volume divided by the follow-up time after the SRS (in days).

Hazard ratios (HRs) for the association between $K_{\text {trans }}$ and midterm tumor progression were obtained using Cox proportional hazard models. For this analysis, the categories "tumor remission" and "stable disease" were grouped as "local control." Other variables analyzed as potential predictive factors were dose of radiation, primary tumor, and gender. As we tested a total of four potential predictive factors, the significance level for multiple comparisons was controlled by applying the Bonferroni correction, and $p \leq 0.01$ was considered to be statistically significant for this analysis. The KaplanMeier survival analysis and the log-rank test were used to assess whether a $K_{\text {trans }}$ increase after SRS was associated with tumor progression. The receiver operating characteristic (ROC) curve, sensitivity, and specificity were then calculated to evaluate the ability of the $K_{\text {trans }}$ ratio to predict the treatment response.

\section{Results}

The baseline study population included 26 patients with 34 brain metastases. Their demographic, clinical, and radiographic data are summarized in Table 1. Nine patients died or developed contraindications to MRI examination such as renal dysfunction or implanted electronic devices during the followup period. Seventeen patients with a total of 22 lesions underwent midterm ( $>16$ weeks) MRI. The mean $( \pm \mathrm{SD})$ follow-up time was $7.9 \pm 4.7$ months (median 6.5 ; range 1.320.3).

The time course of $K_{\text {trans }}$ values and the volume of the metastatic lesions are summarized in Table 2 . The $K_{\text {trans }}$ of the metastatic lesions presented a significant reduction after SRS treatment. The mean $( \pm \mathrm{SD}) K_{\text {trans }}$ value was $0.13 \pm 0.11 \mathrm{~min}^{-1}$ at the baseline and $0.08 \pm 0.07 \mathrm{~min}^{-1}$ at the early posttreatment follow-up $(p<0.001)$. There was a significant positive correlation between the $K_{\text {trans }}$ ratio and the tumor growth ratio (Spearman's coefficient $=0.58, p=0.005$ ). The mean baseline $K_{\text {trans }}$ values were not significantly correlated with the mean midterm tumor volumes. Although there was a trend for reduced tumor volume during follow-up, this was not statistically significant.

In the 17 patients ( 22 lesions) who underwent the midterm ( $>16$ weeks) MRI, 11 (50\%) lesions presented a good response, $2(9 \%)$ lesions were classified as stable, and $9(41 \%)$ of the lesions progressed. An increase in the $K_{\text {trans }}$ ratio was significantly associated with lesion progression (Fig. 1). Each

Table 1 Baseline demographic and clinical characteristics

\begin{tabular}{ll}
\hline Variables & Study group \\
\hline Patients $(N)$ & 26 \\
Lesions $(N)$ & 34 \\
Gender & \\
$\quad$ Male, $N(\%)$ & $14(54)$ \\
$\quad$ Female, $N$ (\%) & $12(46)$ \\
Age, mean \pm SD (range), years & $56.7 \pm 12.8(24-73)$ \\
Radiation dose, median (range), Gy & $19.5(12-25)$ \\
Primary histology & \\
$\quad$ Non-small cell (lung), $N(\%)$ & $16(47)$ \\
$\quad$ Melanoma (skin), $N(\%)$ & $8(23)$ \\
$\quad$ Invasive ductal carcinoma (breast), $N(\%)$ & $4(12)$ \\
$\quad$ Renal cell carcinoma (kidney), $N(\%)$ & $4(12)$ \\
$\quad$ Non-seminomatous germ cell (testicle), $N(\%)$ & $2(6)$ \\
Number of lesions per patient & $19(73)$ \\
$\quad$ Solitary, $N(\%)$ & $7(27)$ \\
$\quad$ Multiple, $N(\%)$ & \\
Localization of lesions & $28(82)$ \\
$\quad$ Supratentorial, $N(\%)$ & $6(18)$ \\
Infratentorial, $N(\%)$ & \\
\hline
\end{tabular}

$N$ number, $S D$ standard deviation 
Table 2 Time course of tumor $K_{\text {trans }}$ and volume

\begin{tabular}{llll}
\hline Parameters & Baseline & $\begin{array}{l}\text { Early follow-up } \\
(4-8 \text { weeks after SRS })\end{array}$ & $\begin{array}{l}\text { Midterm follow-up } \\
(>16 \text { weeks after SRS })\end{array}$ \\
\hline Maximum $K_{\text {trans }}$, mean $( \pm \mathrm{SD}), \mathrm{min}^{-1}$ & $0.13( \pm 0.11)$ & $0.08( \pm 0.07)^{*}$ & NA \\
Tumor volume, median $(\mathrm{Q} 1 ; \mathrm{Q} 3), \mathrm{cm}^{3}$ & $0.65(0.3 ; 1.4)$ & $0.5(0.09 ; 1.7)$ & $0.27(0.03 ; 1.8)$ \\
\hline
\end{tabular}

$S D$ standard deviation, $N A$ not applicable, $Q 1$ first quartile, $Q 3$ third quartile ${ }^{*} p<0.001$

unit increase in the $K_{\text {trans }}$ ratio after SRS was associated with an added risk of $50 \%$ of tumor progression $(\mathrm{HR}=1.50,95 \%$ $\mathrm{CI}=1.16-1.70, p<0.001)$. There was no significant association between the dose of radiation, primary tumor, age, and gender with the midterm tumor outcome.

The $K_{\text {trans }}$ ratio ROC curve for predicting midterm lesion outcomes is shown in Fig. 2. The $K_{\text {trans }}$ ratio showed a sensitivity of $78 \%$ and a specificity of $85 \%$ when a cutoff of 0.15 (increase of $15 \%$ ) was used. Figures 3 and 4 illustrate cases of local control and lesion progression, respectively.

\section{Discussion}

Evaluating the response of brain metastases to SRS on the early post-treatment period is a major challenge that radiologists, neurosurgeons, and radiation oncologists routinely face. The early assessment of treatment response is clinically desirable to determine the need for alternative therapies in unresponsive patients. This study demonstrated that $K_{\text {trans }}$ evaluation using DCE MRI in the early post-treatment period after radiosurgery was able to predict midterm tumor outcome. To our knowledge, this is the first prospective longitudinal study

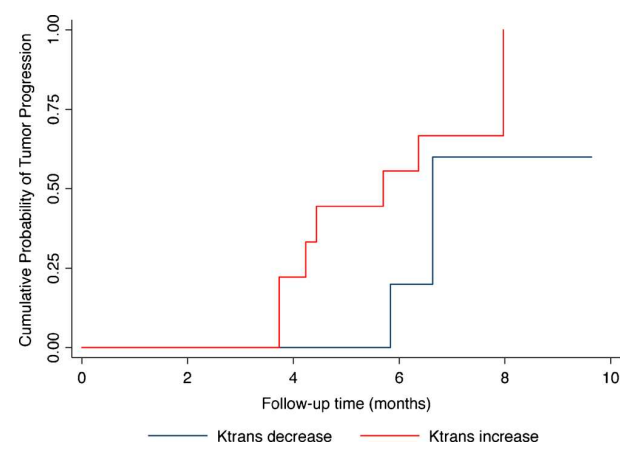

Fig. 1 Kaplan-Meier failure estimating curves of the midterm tumor outcomes comparing groups of lesions with a $K_{\text {trans }}$ increase versus those with a $K_{\text {trans }}$ decrease after stereotactic radiosurgery. Lesions with a $K_{\text {trans }}$ increase had a higher probability of tumor progression and treatment failure $(p=0.04)$ to evaluate the role of DCE MRI for the assessment of patients with cerebral metastases that were treated with SRS.

DCE MRI is a useful technique for the characterization of microvascular function $[9-11,16]$. Currently, the available parameters used to describe tissue permeability, based in compartmental models, include $K_{\text {trans }}$ (transfer constant), $k_{\mathrm{ep}}$ (rate constant), and $v_{\mathrm{e}}$ (interstitial volume) $[10,11,17]$. The advantage of using $K_{\text {trans }}$ as a parameter is the possibility to quantitatively measure the extent of contrast accumulation as a function of time $[10,11] . K_{\text {trans }}$ reflects capillary permeability if inter-compartmental movement of tracer is not primarily restricted by regional blood flow [11]. Specifically for brain tumors, $K_{\text {trans }}$ could be a good measurement for blood-brain barrier integrity [11, 18]. However, the comparison of $K_{\text {trans }}$ literature values is complicated by the use of different image acquisition parameters and different image post-processing models $[11,16]$. This parameter variation hinders the definition of normative reference values for $K_{\text {trans. }}$. The longitudinal design of our study enabled the evaluation of changes in $K_{\text {trans }}$ measurements that occurred in each individual tumor as a result of treatment. Therefore, the $K_{\text {trans }}$ values were likely less affected by the known heterogeneity between different tumor histologies.

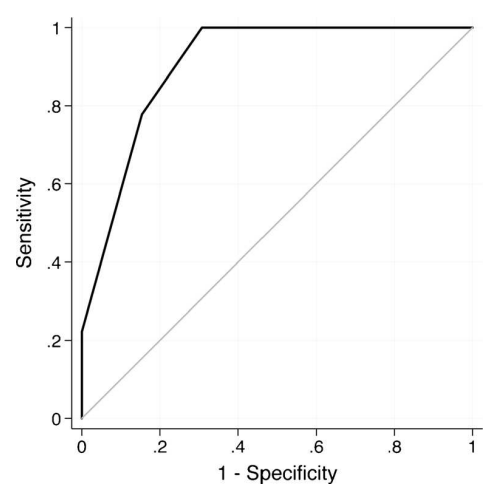

Fig. 2 Receiver operating characteristic (ROC) curve of $K_{\text {trans }}$ ratio for the prediction of midterm lesion outcome. The $K_{\text {trans }}$ ratio presented an area under the ROC curve of 0.86 

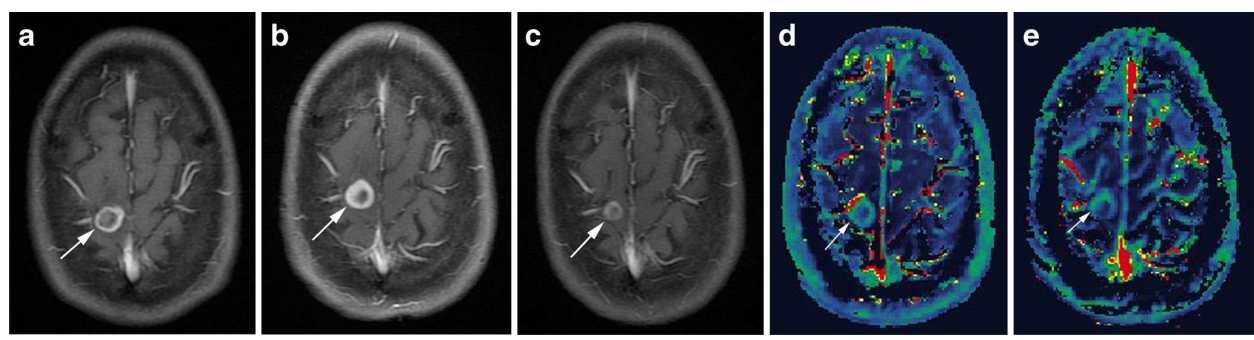

Fig. 3 Local control case. MR images obtained in a 55-year-old male patient with a right frontal lung metastasis (arrows). a-c Axial T1-weighted images at baseline (a), 4-week (b) and 20-week (c) follow up, respectively; d and e Axial parametric $K_{\text {trans }}$ map at baseline (d) and 4-week (e) follow up,

Other MRI techniques were also studied in the literature to measure the integrity of the blood-brain barrier, such as dynamic susceptibility contrast (DSC) and arterial spin labeling (ASL). In DSC MRI, data analysis is limited because it converts signals to contrast agent concentrations [11]. Using this method, $K_{\text {trans }}$ values can be inaccurate in lesions with very leaky blood-brain barrier, including metastases [18]. Another disadvantage of DSC is the capability of measuring only the permeability in the first pass of contrast [18]. Regarding ASL, previous report has concluded that there is not enough precision in the measurement of capillary permeability surface area product using current MR acquisition [19].

In the present study, we observed a significant reduction in $K_{\text {trans }}$ values of cerebral metastases 4 to 8 weeks after SRS. Another study that investigated the effect of radiation therapy on the blood-brain barrier permeability of a primary brain tumor using DCE MRI also described a gradual decrease of $K_{\text {trans }}$ as soon as 1 month after the conclusion of the fractionated radiation therapy [20]. According to experimental studies, the effects of SRS on $K_{\text {trans }}$ values of brain tumors are likely related to the blood-brain barrier changes and vascular damage caused by radiation [17]. In the acute phase ( $24 \mathrm{~h}$ after respectively. At the 4-week follow-up, the tumor showed a $12 \%$ volume increase, while the $K_{\text {trans }}$ value reduced $56 \%$ compared with baseline. At the 21-week follow-up, the tumor volume decreased $78 \%$ relative to baseline. The disease was graded as tumor remission

irradiation), endothelial cell death and apoptosis could increase blood-brain barrier permeability [21]. Subsequently, an occlusive vascular pattern develops, and a gradual decrease in blood-brain barrier permeability is observed. In the early subacute phase (weeks to months), this most likely results from capillary collapse and occlusion secondary to the formation of platelet clusters and thrombi. The fibrinoid degeneration of vascular walls and proliferation of endothelial and pericytic cells are observed in the late phase (months to years) [17, 18, 20, 21].

The $K_{\text {trans }}$ ratio in the early post-treatment period was a significant predictor of midterm tumor outcome. Each unit increase in $K_{\text {trans }}$ ratio was associated with an increase of $50 \%$ in the risk of midterm tumor progression. We also demonstrated that an increase of $\geq 15 \%$ in the $K_{\text {trans }}$ value of brain metastases $4-8$ weeks after radiosurgery predicted treatment failure with $78 \%$ sensitivity and $85 \%$ specificity. Another study that also evaluated the usefulness of DCE MRI in brain tumor response to radiotherapy demonstrated that $K_{\text {trans }}$ measurements performed well in distinguishing between responders and non-responders [17]. However, a direct comparison between the said study and our study is limited because their study sample included only two cases of brain metastases
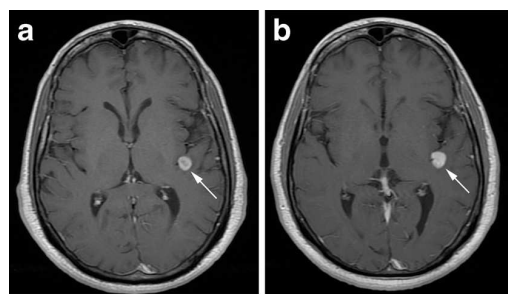

Fig. 4 Progression case. MR images obtained in a 49-year-old male patien with left temporal melanoma metastasis (arrows). a-c Axial T1-weighted images at baseline (a), 4-week (b) and 20-week (c) follow up, respectively; d and e Axial parametric $K_{\text {trans }}$ map at baseline (d) and 4-week (e) follow
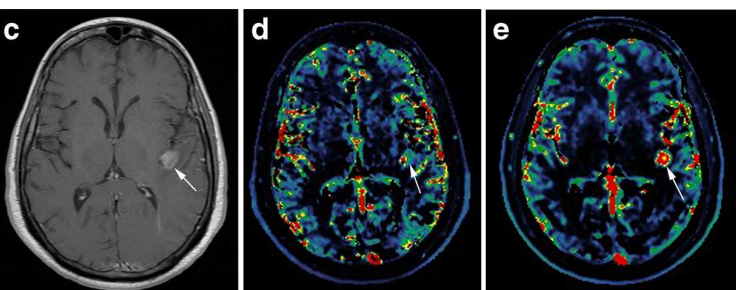

up, respectively. At the 5-week follow-up, compared with baseline, the lesion shows a $57 \%$ volume increase and a $305 \% K_{\text {trans }}$ increase. At the 21-week follow-up, the tumor volume increased $75 \%$ relative to baseline. The disease was graded as tumor progression 
that were treated with whole-brain radiotherapy instead of radiosurgery [17].

Longitudinal MRI scans represent the standard method for monitoring treatment responses after radiosurgery [2-5]. However, a long follow-up period is required for the conventional MRI tumor size measurements to be sufficiently accurate in determining tumor outcome [3-6, 22]. Advanced MRI techniques could potentially play an important role in providing additional information during an earlier stage where alternative therapies may be sought. Recent studies suggested that diffusion- and perfusion-weighted imaging was able to detect brain tumor responses to therapy earlier than conventional MRI [4, 15, 22, 23]. Our finding that an early $K_{\text {trans }}$ increase was associated with an increased risk for tumor progression at midterm MRI follow-up suggests that DCE MRI may also be a valuable tool for the early evaluation of treatment response. It is possible that the combination of these three advanced MRI techniques could show better performance.

This study had limitations. The relatively small sample size and the relatively high number of patients lost prior to followup may have hindered some analyses, such as the midterm impact of SRS on tumor volume. The follow-up period would ideally be longer, and histological evaluation after therapy would be a more suitable outcome for tumor response. However, considering the critical clinical status and prognosis of most patients with brain metastases, invasive interventions should be avoided and are not justifiable. These results should be interpreted with caution because midterm tumor volume ( $>16$ weeks) was the criterion used to classify lesion outcomes; the change in size of a tumor is not a linear process, and metastases have variable regression and growth rates [3]. However, previous studies using similar criteria have demonstrated that initial good responses usually translate to persistent local control on later imaging follow-ups [7].

In summary, this study demonstrates that SRS of cerebral metastasis is associated with a reduction of $K_{\text {trans }}$ values in the early post-treatment period. Furthermore, $K_{\text {trans }}$ variation is predictive of midterm tumor outcome. These results suggest that DCE MRI $K_{\text {trans }}$ may be a valuable biomarker to evaluate treatment responses in the early post-SRS period during which the identification of treatment failure is more critical. Further large-scale studies may provide a proof of the potential capability of this new method and could also evaluate its performance when combined with other MRI techniques.

Acknowledgments DBAF is supported in part by the Coordenação de Aperfeicoamento de Pessoal de Nível Superior (CAPES) PhD student scholarship.

Conflict of interest CCL receives financial support from Guerbet.

\section{References}

1. Ranjan T, Abrey LE (2009) Current management of metastatic brain disease. Neurotherapeutics 6(3):598-603

2. Suh JH (2010) Stereotactic radiosurgery for the management of brain metastases. N Engl J Med 362(12):1119-1127

3. Rahman M, Cox JB, Chi YY et al (2012) Radiographic response of brain metastasis after linear accelerator radiosurgery. Stereotact Funct Neurosurg 90(2):69-78

4. Shah R, Vattoth S, Jacob R et al (2012) Radiation necrosis in the brain: imaging features and differentiation from tumor recurrence. Radiographics 32(5):1343-1359

5. Kang TW, Kim ST, Byun HS et al (2009) Morphological and functional MRI, MRS, perfusion and diffusion changes after radiosurgery of brain metastasis. Eur J Radiol 72(3):370-380

6. Huber PE, Hawighorst H, Fuss M et al (2001) Transient enlargement of contrast uptake on MRI after linear accelerator (linac) stereotactic radiosurgery for brain metastases. Int J Radiat Oncol Biol Phys 49(5): 1339-1349

7. Peterson AM, Meltzer CC, Evanson EJ et al (1999) MR imaging response of brain metastases after gamma knife stereotactic radiosurgery. Radiology 211(3):807-814

8. Ross DA, Sandler HM, Balter JM et al (2002) Imaging changes after stereotactic radiosurgery of primary and secondary malignant brain tumors. J Neurooncol 56(2):175-181

9. Zaharchuk G (2007) Theoretical basis of hemodynamic MR imaging techniques to measure cerebral blood volume, cerebral blood flow, and permeability. AJNR Am J Neuroradiol 28(10):1850-1858

10. Provenzale JM, Mukundan S, Dewhirst M (2005) The role of bloodbrain barrier permeability in brain tumor imaging and therapeutics. brain barrier permeability in brain tumor

11. Kassner A, Thornhill R (2011) Measuring the integrity of the human blood-brain barrier using magnetic resonance imaging. Methods $\mathrm{Mol}$ Biol 686:229-245

12. Zhang N, Zhang L, Qiu B et al (2012) Correlation of volume transfer coefficient $\mathrm{K}^{\text {trans }}$ with histopathologic grades of gliomas. J Magn Reson Imaging 36(2):355-363

13. Weltman E, Salvajoli JV, Brandt RA et al (2000) Radiosurgery for brain metastases: a score index for predicting prognosis. Int J Radiat brain metastases: a score index for

14. Tofts PS, Kermode AG (1991) Measurement of the bloodbrain barrier permeability and leakage space using dynamic MR imaging. 1. Fundamental concepts. Magn Reson Med 17(2):357-367

15. Essig M, Waschkies M, Wenz F et al (2003) Assessment of brain metastases with dynamic susceptibility-weighted contrast-enhanced MR imaging: initial results. Radiology 228(1):193-199

16. Thompson G, Mills SJ, Stivaros SM, Jackson A (2010) Imaging of brain tumors: perfusion/permeability. Neuroimaging Clin N Am
buting of 20(3):337-353

17. Peng SL, Chen CF, Liu HL, et al. (2012) Analysis of parametric histogram from dynamic contrast-enhanced MRI: application in evaluating brain tumor response to radiotherapy. NMR Biomed

18. Lacerda S, Law M (2009) Magnetic resonance perfusion and permeability imaging in brain tumors. Neuroimaging Clin N Am 19(4): 527-557

19. Carr JP, Buckley DL, Tessier J, Parker GJ (2007) What levels of precision are achievable for quantification of perfusion and capillary permeability surface area product using ASL? Magn Reson Med 58(2):281-289 
20. Cao Y, Tsien CI, Sundgren PC et al (2009) Dynamic contrastenhanced magnetic resonance imaging as a biomarker for prediction of radiation-induced neurocognitive dysfunction. Clin Cancer Res 15(5):1747-1754

21. Shinoda J, Yano H, Ando H et al (2002) Radiological response and histological changes in malignant astrocytic tumors after stereotactic radiosurgery. Brain Tumor Pathol 19(2):83-92
22. Gao X, Zhang XN, Zhang YT et al (2011) Magnetic resonance imaging in assessment of treatment response of gamma knife for brain tumors. Chin Med J (Engl) 124(12):1906-1910

23. Huang CF, Chou HH, Tu HT et al (2008) Diffusion magnetic resonance imaging as an evaluation of the response of brain metastase treated by stereotactic radiosurgery. Surg Neurol 69(1):62-68, discussion 8 


\section{BIBLIOGRAFIA CONSULTADA}

Rother ET, Braga MER. Como elaborar sua tese: estrutura e referências. São Paulo; 2001.

Divisão de Biblioteca e Documentação da Faculdade de Medicina da Universidade de São Paulo. Guia apresentação de dissertações, teses e monografias. São Paulo; 2011. 